\title{
Application of Hilbert-Huang Transform in Structural Health Monitoring: A State-of-the-Art Review
}

\author{
Bo Chen, ${ }^{1}$ Sheng-lin Zhao, ${ }^{1}$ and Peng-yun $\mathrm{Li}^{2}$ \\ ${ }^{1}$ Key Laboratory of Roadway Bridge and Structural Engineering, Wuhan University of Technology, Wuhan 430070, China \\ ${ }^{2}$ Guangdong Power Grid Corporation Co., Ltd., Guangzhou 510080, China \\ Correspondence should be addressed to Bo Chen; cbsteven@163.com
}

Received 26 January 2014; Accepted 28 February 2014; Published 2 June 2014

Academic Editor: Ting-Hua Yi

Copyright (c) 2014 Bo Chen et al. This is an open access article distributed under the Creative Commons Attribution License, which permits unrestricted use, distribution, and reproduction in any medium, provided the original work is properly cited.

\begin{abstract}
This paper reviews the development and application of HHT in the field of SHM in the last two decades. The challenges and future trends in the development of HHT based techniques for the SHM of civil engineering structures are also put forward. It also reviews the basic principle of the HHT method, which contains the extraction of the intrinsic mode function (IMF), mechanism of the EMD, and the features of HT; shows the application of HHT in the system identification, which contains the introduction of theoretical method, the identification of modal parameters, and the system identification on real structures; and discusses the structural damage detection using HHT based approaches, which includes the detection of common damage events, sudden damage events, and cracks and flaws.
\end{abstract}

\section{Introduction}

Structural health monitoring (SHM) is the process of establishing some knowledge of the current structural conditions or implementing a damage detection strategy for aerospace, civil, and mechanical engineering infrastructures. The SHM process involves the operational evaluation, data acquisition, fusion and cleansing, and feature extraction and discrimination [1-3]. The interest in the ability to monitor a structure and identify structural parameters and damages at the earliest possible stage is pervasive throughout the civil, mechanical, and aerospace engineering communities [4-6]. Doebling et al. [7, 8] and Sohn et al. [9] gave comprehensive reviews on system identification and damage detection. With regard to the algorithm used, these identification methods can be classified into index methods, model updating methods, and signal based methods [10].

The widely used vibration based damage assessment methods require modal properties that are obtained from signals via the traditional Fourier transform (FT). There are a few inherent characteristics of FT that might affect the accuracy of system identification and damage detection. Firstly, the FT is in fact a data reduction process and information about the structural health condition might be lost during the process [8]. Also, the FT is not able to present the time dependency of signals and it cannot capture the evolutionary characteristics that are commonly observed in the signals measured from naturally excited structures [11]. Damage is typically a local phenomenon which tends to be captured by higher frequency modes $[12,13]$. These higher natural frequencies normally are closely spaced but poorly excited [14]. All these factors add difficulties to the implementation aspect of the FT based damage detection techniques. To overcome this shortcoming, many signal based identification methods like wavelet transform (WT) [15-17], autoregressive moving-average family models, Hilbert-Huang transform (HHT), and so forth have been developed and applied in the SHM in recent years.

Huang et al. [18-20] firstly developed a new method named HHT for analyzing nonlinear and nonstationary data. HHT method consists of empirical mode decomposition (EMD) and Hilbert transform (HT). The most innovative idea is the introduction of EMD method with which any complicated set of data can be decomposed into a finite 
and often small number of intrinsic mode functions (IMF) that admit well-behaved HT. Since the EMD is based on the local characteristic time scale of the original data, this decomposition method is adaptive and highly efficient. The HHT method has then been quickly used in many scientific and engineering disciplines to give new insights into the nonstationary and nonlinear physical phenomena [21]. The HHT method has been used in structural engineering analysis, especially for SHM. Application of HHT to SHM was firstly investigated by Vincent et al. [22] and then Yang et al. [23-25] used HHT to carry out the system identification and damage detection. After that, the application of HHT based approaches in the SHM has attracted more and more attention across the world and a great number of studies are conducted from the aspects of theory and experiment and field measurement. However, there are still many challenges and difficulties concerning the HHT based monitoring, detection, and assessment techniques for practical application of SHM in various civil engineering structures. Therefore, it is still imperative to investigate the feasibility, validity, and applicability of the HHT based approaches in SHM.

This paper reviews the development and application of HHT in the field of SHM in the last two decades. The challenges and future trends in the development of HHT based techniques for the SHM of civil engineering structures are also put forward. The structure of the rest of the paper is as follows. Section 2 reviews the basic principle of the HHT method, which contains the extraction of the intrinsic mode function (IMF), mechanism of the EMD and the features of HT; Section 3 reviews the application of HHT in the system identification, which contains the introduction of theoretical method, the identification of modal parameters, and the system identification on real structures; Section 4 discusses the structural damage detection using HHT based approaches, which includes the detection of common damage events, sudden damage events, and cracks and flaws. The experiment and field measurement of the HHT based damage detection is also demonstrated. Finally, the challenges and future trends in the development of HHT based approaches for structural health monitoring are summarized in the conclusions.

\section{Hilbert-Huang Transform}

2.1. Intrinsic Mode Function. As a new method capable of dealing with both nonstationary and nonlinear data, the EMD approach is intuitive, direct, a posteriori, and adaptive [18-20]. The decomposition is conducted based on a simple assumption that any data consist of different simple intrinsic modes of oscillations. Each mode may or may not be linear and will have the same number of extrema and zero crossings. Additionally, the oscillation will also be symmetric with respect to the "local mean." The mean is defined through the envelopes without resorting to any time scale. Each mode should be independent of the others after decomposition, which is designated as an IMF.

An IMF is defined as a function that satisfies two conditions: (1) within the data range, the number of extrema and the number of zero crossings are equal or differ at most by one and (2) at any point, the mean value of the envelope defined by the local maxima and the envelope defined by the local minima is zero. The intrinsic mode function is defined to represent the oscillation mode imbedded in the signal. An IMF is not restricted to a narrowband signal, and it can be both amplitude- and frequency-modulated. In reality, the signal can be nonstationary.

2.2. Empirical Mode Decomposition. The EMD method is also named as characteristic scale decomposition method [19] and is initially designed as a processing step to extract simple oscillatory functions from the signal. Any data set can be decomposed into several IMFs by a procedure called sifting process. The decomposition is based on the assumptions: (1) the signal has at least two extrema-one maximum and one minimum; (2) the characteristic time scale is defined by the time lapse between the extrema; and (3) if the data were totally devoid of extrema but contained only inflection points, then it can be differentiated once or more times to reveal the extrema. Final results can be obtained by integration(s) of the components.

A short segment of wind speed time history from field measurement is shown in Figure 1(a) and is used to depict the sifting process of the EMD. The decomposition method can simply use the envelopes defined by the local maxima and minima separately. After identifying all the local extrema in the original data $X(t)$, connect all the local maxima by a cubic spline to produce the upper envelope. Repeat the procedure for the local minima to produce the lower envelope. The mean of these two envelopes (red solid line) is designated as $m_{1}$ (blue solid line) and the difference between the data and $m_{1}$ is the first component, $h_{1}$ :

$$
h_{1}(t)=X(t)-m_{1}(t) .
$$

The mean of these two envelopes (red solid line) is designated as $m_{1}$ (blue solid line) and the difference between $x$ and $m_{1}$ is designated as $h_{11}$, where the superscript indicate the local sifting times. The component $h_{1}(t)$ is then examined to see if it satisfies the above-mentioned two requirements to be an IMF. If not, the sifting process is to be repeated by treating $h_{1}(t)$ as a new time history for $k$ times until $h_{1}(t)$ is an IMF, designated as $c_{1}(t)$. Then, the first IMF is separated from the original time history, giving a residue $r_{1}(t)$ as

$$
r_{1}(t)=X(t)-c_{1}(t) .
$$

The sifting process is applied successively to each subsequent residue to obtain the subsequent IMFs until either the residue $r_{n}(t)$ is smaller than a predetermined value or it becomes a monotonic function. The original time history is finally expressed as the sum of the IMF components plus the final residue:

$$
X(t)=\sum_{j=1}^{n} c_{j}(t)+r_{n}(t),
$$

where $c_{j}(t)$ is the $j$ th IMF component; $n$ is the total number of IMF components; and $r_{n}(t)$ is the final residue. After 


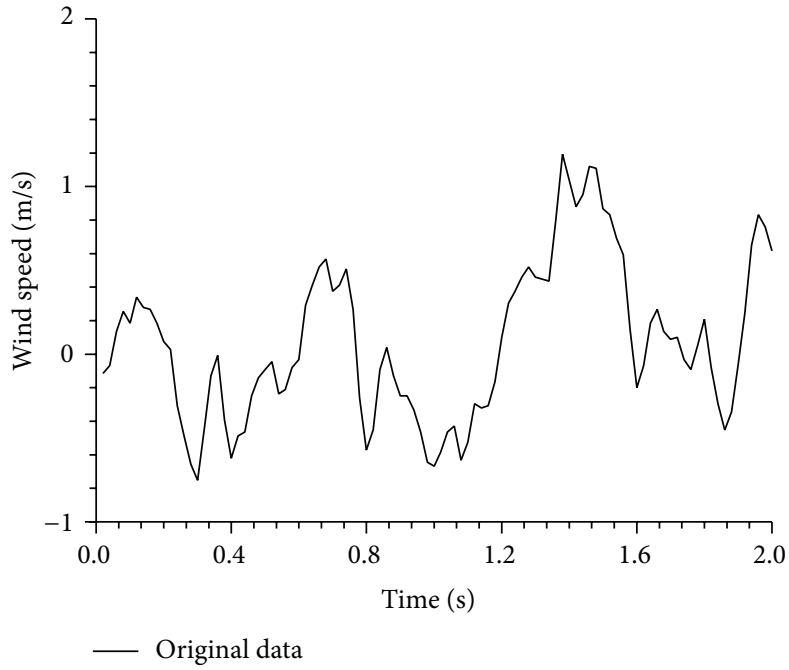

(a) Original data

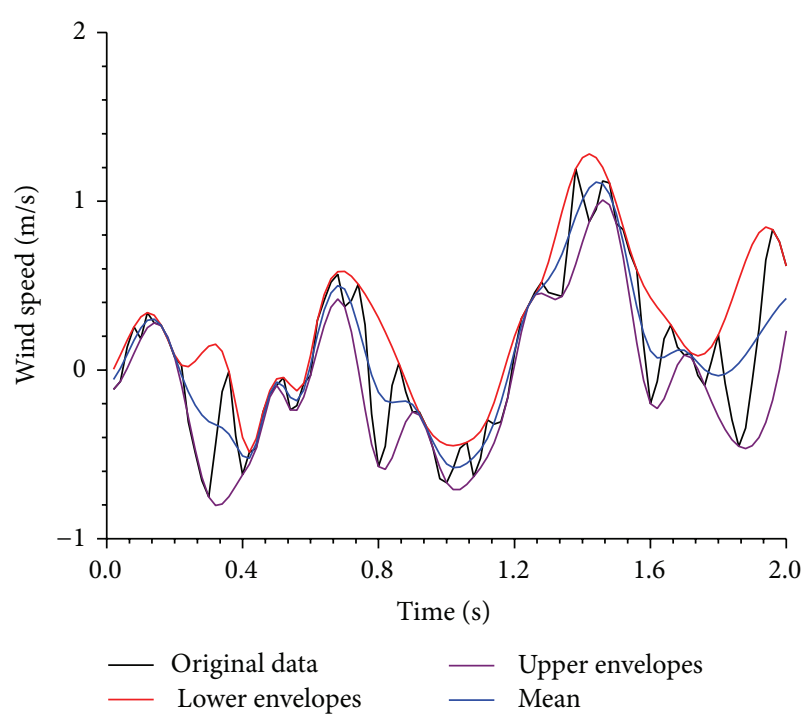

(b) Sifting process

FIGURE 1: Illustration of the sifting process.

the decomposition, the first IMF component obtained has the highest frequency content of the original time history while the final residue represents the component of the lowest frequency in the time history.

It is clear that the process is similar to sifting: to separate the finest local mode from the data at first based on the characteristic time scale. The sifting process should be performed carefully for carrying out the process to extremes could make the resulting IMF a pure frequency modulated signal of a constant amplitude. To guarantee that the IMF components retain enough physical sense of both amplitude and frequency modulations, Huang et al. proposed a criterion for the sifting process to stop by limiting the size of the standard deviation, SD, computed from the two consecutive sifting results as

$$
\mathrm{SD}=\sum_{t=1}^{T}\left[\frac{\left|h_{1(k-1)}(t)-h_{1 k}(t)\right|^{2}}{h_{1(k-1)}^{2}(t)}\right] .
$$

A typical value for SD can be set between 0.2 and 0.3 . During the sifting process, a criterion called intermittency check [20] can be imposed for each IMF component in order to limit its frequency content. This criterion works by specifying a frequency, termed intermittency frequency $f_{c}$, for each IMF component during its sifting process, so that the data having frequencies lower than $f_{c}$ will be removed from the resulting IMF.

2.3. Hilbert Transform. Having obtained the IMF components from the time history $X(t)$, the second step of the HHT method is implemented by performing the HT to each IMF component. HT has long been used for linear and nonlinear vibration systems identification for many years. The amplitude, instantaneous phase, and time-varying frequency can be determined by applying HT to vibration signals to identify the properties of a vibration system. The HT of a real-valued function $X(t)$ in the range $-\infty<t<\infty$ is a real-valued function $\tilde{y}(t)$ defined by Bendat and Piersol [26]

$$
Y(t)=H[X(t)]=\int_{-\infty}^{\infty} \frac{X(u)}{\pi(t-u)} d u,
$$

where $H$ denotes the HT operator. The HT is the convolution of $y(t)$ with $1 / t$, which emphasizes the local properties of the data signal. The corresponding analytical signal $Z(t)$ can then be defined as

$$
\begin{gathered}
Z(t)=X(t)+i Y(t)=A(t) e^{i \theta(t),} \\
A(t)=\left[X^{2}(t)+Y^{2}(t)\right]^{1 / 2}, \\
\theta(t)=\tan ^{-1}\left[\frac{Y(t)}{X(t)}\right],
\end{gathered}
$$

where $A(t)$ and $\theta(t)$ are defined as the amplitude and instantaneous phase angle of $X(t)$, respectively and $i$ is the imaginary unit. The instantaneous frequency $\omega(t)$ is then given by

$$
\omega(t)=\frac{d \theta(t)}{d t} .
$$

There is only a single frequency $\omega$ at any time $t$ if the general signal $X(t)$ is processed through the HT. For a general signal $X(t)$ at any time $t$, there is a distribution of frequencies at that moment rather than just a single frequency. Consequently, Huang et al. [19] pointed out that the definition of instantaneous frequency for a signal has physical significance only if it is an IMF. This is the reason why a signal is decomposed into the IMFs using the EMD method before applying the HT. After applying the HT to each IMF component $c_{j}(j=1,2, \ldots, N)$, the original time history 
excluding the final residue can be then expressed as the real part $(\mathrm{Re})$ of the sum of the HT of all the IMF components:

$$
X(t)=\operatorname{Re} \sum_{j=1}^{N} a_{j}(t) e^{i \int \omega_{j}(t) d t}
$$

where $a_{j}(t)$ and $\omega_{j}(t)$ are the amplitude and frequency of the $i$ th IMF component, respectively. Thus, the amplitude is not only the function of time but also the function of frequency. The frequency-time distribution of the amplitude is designated the Hilbert amplitude spectrum, $H(\omega, t)$, or simply the Hilbert spectrum, from which the inherent characteristics of a nonlinear and/or nonstationary time history can be identified.

\section{System Identification}

As a new signal processing approach, the HHT has been widely utilized in the field of vibration engineering. The dynamic responses can be analyzed by using EMD in conjunction with HT to depict the structural modal responses. Identification of system parameters from vibration measurements is one of the most attractive research topics in the structural health monitoring area. The theoretical method, identification approaches, and application in various civil engineering structures of the HHT-based modal identification method are briefly reviewed in Section 3.1.

3.1. Theoretical Method. Yang et al. [27] proposed the method to identify multidegree-of-freedom (MDOF) linear systems using measured free vibration time histories based on the HHT. The measured dynamic responses with noise contamination are decomposed into modal responses using the EMD with intermittency criteria. The Hilbert transform is applied to each modal response to obtain the instantaneous amplitude and phase angle time histories. A linear least-square fit procedure is utilized to identify the natural frequency and damping ratio from the instantaneous amplitude and phase angle for each modal response. The natural frequencies, damping ratios, and mode shapes can be identified based on the free vibration responses. The measured impulse acceleration responses $\ddot{z}_{p}(t)$ at $p$ th DOF for a $n$-DOF structure can be expressed as

$$
\ddot{z}_{p}(t)=\sum_{j=1}^{n} \ddot{x}_{p j}(t)+v_{p}(t),
$$

where $\ddot{x}_{p j}(t)$ is the impulse acceleration response at the $p$ th DOF of the $j$ th mode and $v_{p}(t)$ is a band-limited Gaussian white-noise process with zero mean. The modal response $\ddot{x}_{p j}(t)$ is restricted to a frequency band around the $j$ th natural frequency $\omega_{j}$. Hence, the approximate frequency range for each natural frequency, $\omega_{j L}<\omega<\omega_{j H}$, can be determined based on the Fourier spectrum or Hilbert-Huang marginal spectrum with the aiding of intermittency criteria (Yang and Lei 1998). Firstly, the measured response signal $\ddot{z}_{p}(t)$ is decomposed using EMD with an intermittency frequency $\omega_{j H}$ to obtain all IMFs that have frequencies greater than $\omega_{j H}$. Secondly, remove all IMFs obtained from the signal $\ddot{z}_{p}(t)$ and the resulting signal $\ddot{z}_{p j}^{*}(t)$ contains frequencies lower than $\omega_{j H}$. Thirdly, process $\ddot{z}_{p j}^{*}(t)$ through EMD with an intermittency frequency $\omega_{j L}$ to obtain the first IMF, which is approximately the $j$ th modal response. Then, repeat the process successively starting from the $j=n$ to $j=1$ to obtain $n$ modal responses $\ddot{x}_{p j}(t)(j=1,2, \ldots, n)$. This process can extract the modal response $\ddot{x}_{p j}(t)$ as an IMF and simultaneously remove all the noises outside the frequency range, $\omega_{j L}<\omega<\omega_{j H}$, of each mode. Therefore, the measured response $\ddot{z}_{p}(t)$ can be decomposed into $n$ modal response functions and many other IMFs as follows:

$$
\ddot{z}_{p}(t) \approx \sum_{j=1}^{n} \ddot{x}_{p j}(t)+\sum_{j=1}^{m-n} c_{p j}(t)+r_{p}(t) .
$$

By introducing the logarithmic and differential operators, the relationship between circular frequency and damping ratios can be expressed as

$$
\begin{gathered}
\ln A_{j}(t)=-\xi_{j} \omega_{j} t+\ln B_{j, k}(t), \\
\omega_{j}(t)=\frac{d \theta_{j}(t)}{d t}=\omega_{d j}(t)=\omega_{j}(t) \sqrt{1-\xi_{j}^{2}},
\end{gathered}
$$

where $A_{j}(t)$ and $\theta_{j}(t)$ are the instantaneous amplitude and instantaneous phase angle of the $j$ th mode shape, respectively; $\omega_{j}(t)$ and $\omega_{d j}(t)$ are the circular frequency and damped frequency of the $j$ th mode shape; $\xi_{j}$ is damping ratio of the $j$ th mode shape; and $B_{j, k}(t)$ is a constant that depends on the intensity of impulsive loading and the mass and frequency of the system.

3.2. Identification of System Parameters. The damped circular frequency $\omega_{d j}(t)$ can be identified from the instantaneous frequency $\omega_{j}(t)$. The damping ratio $\xi_{j}$ can be identified with the identified $\omega_{d j}(t)$ and the slope $-\xi_{j} \omega_{j}(t)$ of the straight line of the decaying amplitude $A_{j}(t)$ in a semilogarithmic scale. It is found that the instantaneous frequency may fluctuate around its mean value due to the amplitude variation of the signal [19] and the requirement for small damping ratio may limit the application of the HT method. Therefore, Yang and Lei [23] proposed a procedure for the system identification based on the HT method: (1) determine the damped frequency $\omega_{d j}(t)$ from the slope of the phase function $\theta_{j}(t)$ using a linear least-squares fitting technique and (2) determine the damping ratio $\xi_{j}$ by applying the linear leastsquares fitting technique to the decaying amplitude $A_{j}(t)$ in a semilogarithmic scale.

3.2.1. Structures with Common Modal Properties. Yang et al. $[23-25,27]$ examined the performance of the proposed identification approach using three linear systems with different dynamic characteristics. Numerical simulation results demonstrated that the proposed system identification method yields quite accurate results, and it offers a new and effective tool for the system identification of linear structures in which normal modes exist. For all the numerical examples 
TABLE 1: Comparison on modal identification of a shear building with light appendage.

\begin{tabular}{|c|c|c|c|c|c|c|}
\hline & \multicolumn{3}{|c|}{ Damped frequency $(\mathrm{Hz})$} & \multicolumn{3}{|c|}{ Damping ratio } \\
\hline & Theoretical value $(\mathrm{Hz})$ & FFT & HHT & Theoretical value & Bandwidth method & HHT \\
\hline Model & 0.1836 & 0.1892 & 0.1838 & $1 \%$ & $1.23 \%$ & $1.01 \%$ \\
\hline Mode2 & 0.1956 & 0.1953 & 0.1936 & $1 \%$ & $1.52 \%$ & $1.13 \%$ \\
\hline Mode3 & 0.5419 & 0.5416 & 0.5505 & $1 \%$ & $1.80 \%$ & $1.09 \%$ \\
\hline Mode4 & 0.5727 & 0.5722 & 0.5706 & $1 \%$ & $1.86 \%$ & $1.07 \%$ \\
\hline
\end{tabular}

considered, including a 3-DOF model building and a 4-DOF mechanical system, only one measured acceleration signal (one sensor) is sufficient to identify all the natural frequencies and damping ratios. The variation of estimated $\omega_{j}$ and $\xi_{j}$ based on different measured signals is very small.

In addition, Yang et al. [28] presented a method of identifying natural frequencies and damping ratios of in situ tall buildings using ambient wind vibration data. The approach is based on the combination of the EMD, the random decrement technique (RDT), and the HHT and requires the responses of only one acceleration sensor. The application of the proposed methodology is demonstrated in detail using simulated response data of a 76-story benchmark building polluted by noise. Simulation results demonstrate that the accuracy of the proposed method in identifying natural frequencies and damping ratios is remarkable. This procedure was also utilized by Poon and Chang $[29,30]$ and Cui et al. [31] to identify the normal modes of an MDOF structures.

Yan and Miyamoto [32] carried out a comparative investigation of modal parameter identification based on the improved HHT and WT using the modified complex Morlet wavelet function. The capabilities of these two techniques are compared and assessed by using three examples, namely, a numerical simulation for a damped system with two very close modes, an impact test on an experimental model with three well-separated modes, and an ambient vibration test on the Z24-bridge benchmark problem. The made observations indicate that for the system with well-separated modes both methods are applicable when the time-frequency resolutions are sufficiently taken into account.

In addition, Yang et al. [33] extended the identification approach for normal modes to identify general linear structures with complex modes using the free vibration response data polluted by noise in the similar way. Measured response signals are first decomposed into modal responses using the EMD with intermittency criteria. Each modal response contains the contribution of a complex conjugate pair of modes with a unique frequency and a damping ratio. Then, each modal response is decomposed in the frequency-time domain to yield instantaneous phase angle and amplitude using the HT. The complex eigenvalues of the linear structure can be identified based on a single measurement of the impulse response time history at one appropriate location.

3.2.2. Structures with Closely Spaced Modal Frequencies. The system identification problem is quite challenging for a structure involving closely spaced modes and has attracted attention in the vibration field. Chen and $\mathrm{Xu}[34,35]$ firstly

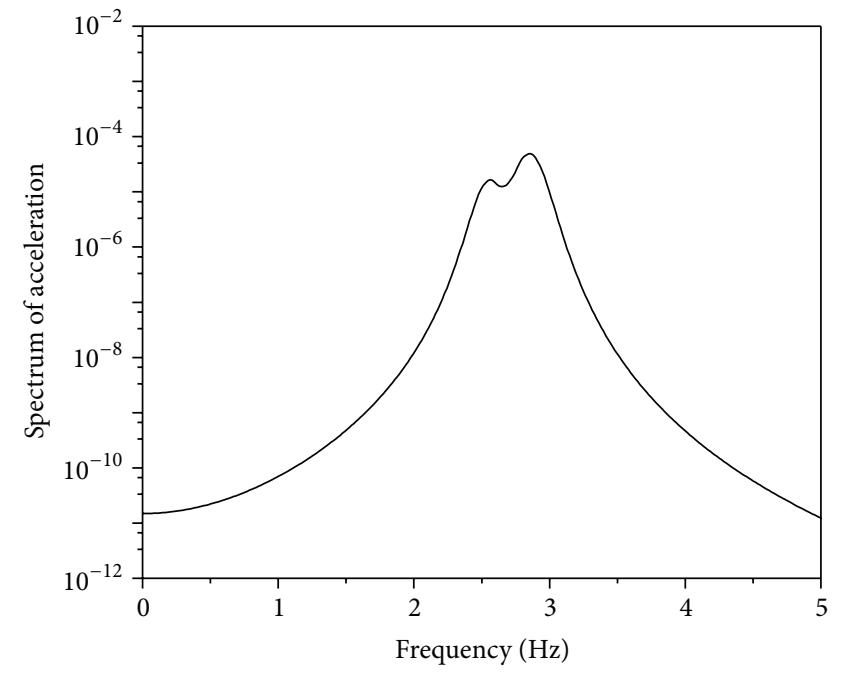

FIgURE 2: Power spectrum for the 2-DOF system.

explored the possibility of using the HHT method to identify the modal damping ratios of the structure with closely spaced modal frequencies. The procedure of using the HHT method for modal damping ratio identification suggested by Yang and Lei [23] is adopted with some modification in respect of intermittency check. The dynamic response of a 2-DOF system under an impact load (see Figure 2) is then computed for a wide range of dynamic properties from well-separated modal frequencies to very closely spaced modal frequencies. The natural frequencies and modal damping ratios identified by the HHT method are compared with the theoretical values and those identified using the fast Fourier transform (FFT) method. The results show that the HHT method is superior to the FFT method in the identification of modal damping ratios of the structure with closely spaced modes of vibration. A 36-story shear building with a 4-story light appendage, having closely spaced modal frequencies and subjected to an ambient ground motion, is also analyzed to investigate the applicability of the HHT approach. It is seen from Table 1 that the detection quality of damping ratios based on the HHT approach is much better than that using the bandwidth method. Zheng et al. [36] developed an improved approach by using the singular-value decomposition as a signal preprocessing technique of HHT to extract modal parameters for closely spaced modes and low-energy components. The proposed method is applied to a simulated airplane model and the results demonstrate the validity of the approach. 


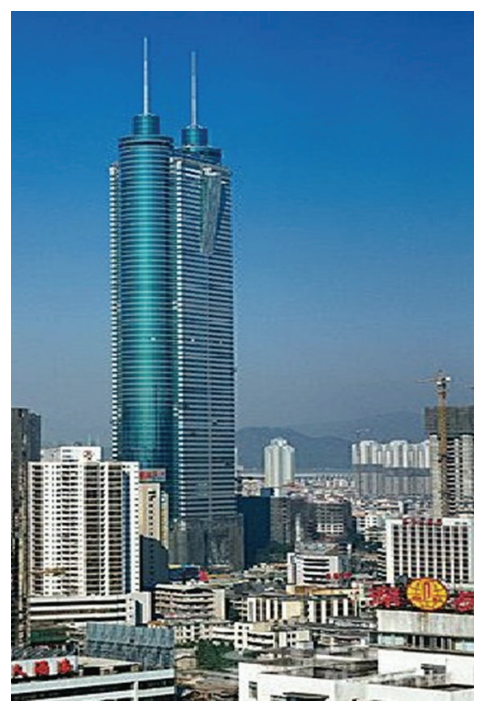

(a) Di Wang Building

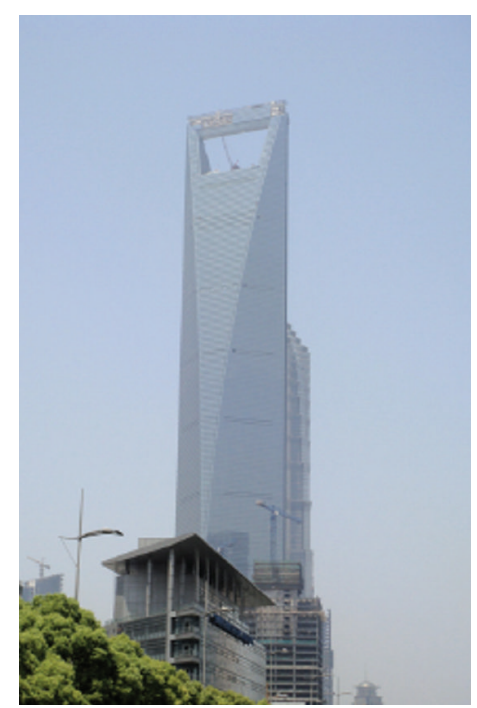

(b) Shanghai World Financial Center

FIGURE 3: Elevation of supertall buildings.

3.2.3. Improved Identification Approaches. Besides the application of the method developed by Yang et al., many improved approaches are developed and applied in the modal identification. A posteriori adaptive energy-based frequencyamplitude method is proposed by $\mathrm{Li}$ and Bao [37] for frequency identification. A series of bandpass filtering are carried out first and then the forward energy weighted frequency and the backward frequency weighted amplitude are obtained and the natural frequencies can be identified by plotting the obtained weighted amplitude against the weighted frequency. Ong et al. [38] proposed an innovative HHT based frequency identification approach designated as adaptive magnitude spectrum algorithm. Two numerically simulated examples, that is, the free vibration signal from a concrete slab subjected to impact loading and the random vibration signal generated by the Phase I ASCE structural health monitoring analytical benchmark problem, and one experimental example, that is, the free vibration signal based on the Phase II ASCE structural heath monitoring experimental benchmark problem, are used to demonstrate the efficacy of the algorithm.

Bahar and Ramezani [39] proposed a new enhanced HHT to avoid mathematical limitations of the Hilbert spectral analysis; an additional parameter is employed to reduce the noise effects on the instantaneous frequencies of IMFs. The efficacy of the proposed method is demonstrated based on two case studies: a typical 3-DOF model subjected to a random excitation and a real 15-story building under ambient excitation. Wu et al. [40] presented a new decentralized data processing approach for modal identification using the HHT. It is shown that this method is suitable for implementation in the intrinsically distributed computing environment found in wireless smart sensor networks. The effectiveness of the proposed techniques is demonstrated through a set of numerical studies and experimental validations on an in-house cable-stayed bridge model in terms of the accuracy of identified dynamic properties.

\subsection{System Identification on Real Structures}

3.3.1. High-Rise Structures. It is difficult to artificially excite the large-scale civil engineering structures for model testing and identification. Therefore, the structural dynamic responses subjected to ambient excitations are commonly utilized for modal identification [41]. As mentioned above, Yang and Lei $[23,24]$ successfully applied the HHT method together with the RDT to identify the modal parameters of linear structures. However, this approach has not been examined yet using field measurement data of large-scale real structures until the field measurement and identification were conducted by $\mathrm{Xu}$ et al. $[42,43]$ by taking a $384 \mathrm{~m}$ super-tall building, the Di Wang Building with 69 storeys as the example structure as shown in Figure 3(a). A wind and structural monitoring system was installed in the Di Wang Building. The monitoring system timely recorded wind and structural response data during typhoon York in September 1999. Xu et al. applied the HHT method in conjunction with the RDT to the measured data to identify dynamic characteristics of the Di Wang Building. A series of natural frequencies and modal damping ratios of the building under different wind speeds in different directions are identified and in comparison with those from the FFT based method. The variations of natural frequency, total modal damping ratio, and net structural modal damping ratio with wind speed and vibration amplitude are also investigated. The results indicate that the natural frequencies identified by the HHT method are almost the same as those from the FFT method. The modal damping ratios identified by the HHT method indicate that the FFT based bandwidth method may significantly overestimate the first lateral and longitudinal modal damping ratios of the building. 


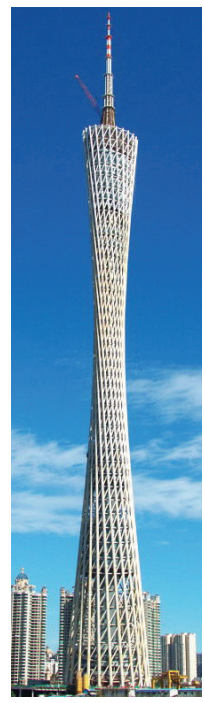

(a) Elevation

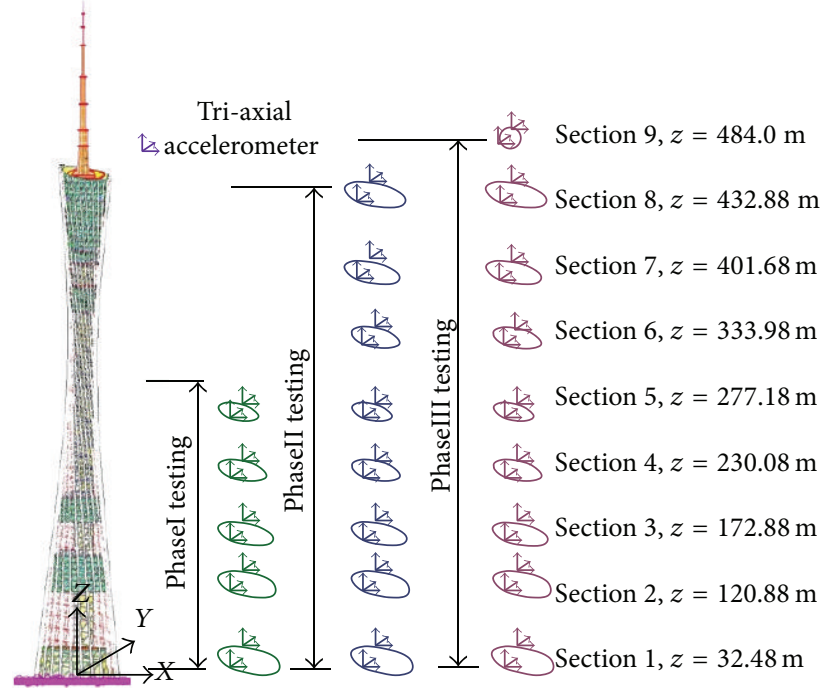

(b) Three phases for ambient vibration measurement

Figure 4: Guangzhou New TV Tower.

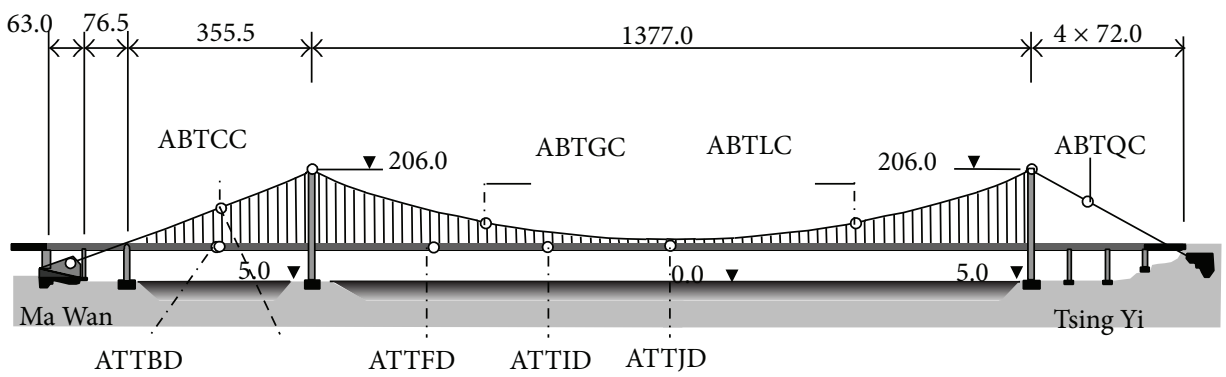

FIgURE 5: Configuration of the Tsing Ma Suspension Bridge.

Similar approach was utilized by the Shi et al. [44] to investigate the modal properties of a 101-storey building both from free and ambient vibration responses. The supertall building is the Shanghai World Financial Center which is $492 \mathrm{~m}$ above ground as shown in Figure 3(b). Three modal identification techniques are applied to the ambient and forced vibration measurements for identifying the dynamic properties of the building. These methods are the peakpicking method combined with the half-power bandwidth method in the frequency domain, the RDT with logarithmicdecrement method in the time domain, and the HHT method in the time-frequency domain. The modal frequencies from the finite element analysis and the shaking table test are further studied with the results of field test. The effect of the installed active tuned mass damper on the damping characteristics of the building is presented. The made observation indicates that the discrepancy of the estimated damping ratios under ambient vibration is relatively larger than that of the natural frequencies.

More recently, a supertall tower with a height of $610 \mathrm{~m}$, the Guangzhou New TV Tower (GNTVT), is constructed in Guangzhou, China, as shown in Figure 4. A sophisticated SHM system consisting of over 800 sensors was designed and implemented for both in-construction and in-service real-time monitoring [45]. This implemented SHM system has monitored the structural responses of the GNTVT after completion of its construction under different loadings, such as typhoons and earthquakes. Ambient vibration tests were conducted at two different construction stages and completed stage. The modal frequencies and damping ratios under different loadings was identified using the measured acceleration responses [46]. The HHT technique is applied to obtain the instantaneous frequencies and energy distribution under different loadings in the time-frequency domain and the results are compared with those from wavelet transform to prove the validity.

3.3.2. Bridges. The system identification of the Di Wang Building in southern China was performed using the HHT under the disturbed of the typhoon York, which also attacked the civil engineering structures in the nearby Hong Kong. The Tsing Ma Suspension Bridge has a total span of $2132 \mathrm{~m}$ and carries a dual three-lane highway and two railway tracks as shown in Figure 5. A Wind and Structural Health Monitoring System for the Tsing Ma Bridge has been devised, installed, and operated since 1997. About 280 sensors were installed at different locations on the bridge for collecting various types of structural and environmental information [47, 48]. 


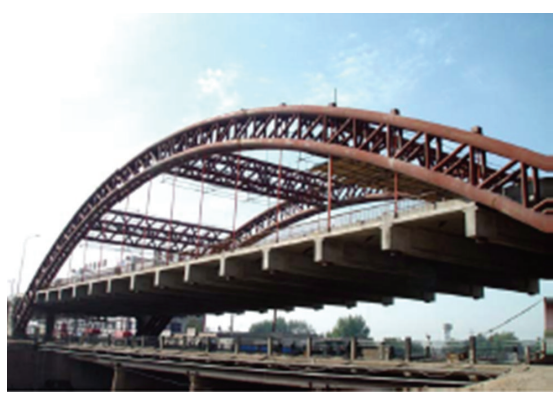

(a) Xining Beichuan Arch Bridge

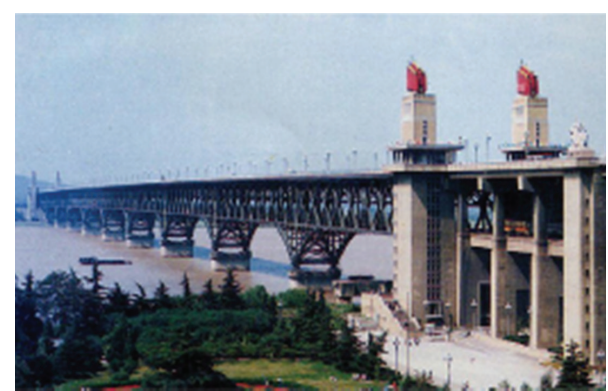

(b) Nanjing Yangtze River Bridge

FIGURE 6: Configuration of the example bridges.

Therefore, the modal identification procedure utilized for the Di Wang Building under typhoon York was also carried out by Chen et al. [49] for identifying bridge modal properties at first. Natural frequencies and modal damping ratios were identified from both stationary and nonstationary records showing that the consistency of the identification results among sensors installed on deck and/or on cables is satisfied. The modal damping ratios given by the HHT method are lower than those given by the FFT-based method, which may indicate that the FFT method overestimates the modal damping ratios. The variations of natural frequency and total modal damping ratio with vibration amplitude and mean wind speed are also examined. The result shows that the natural frequency decreases with the increase of wind speed and vibration amplitude.

The modal identification approach based on HHT developed by Yang and Lei was extended by Yu and Ren [50] by developing an EMD-based stochastic subspace identification of structures from operational vibration measurements. The stochastic subspace identification method is applied to the decomposed signals and yields the modal parameters. A large span arch bridge constructed in China as shown in Figure 6(a) is taken as the example structure to investigate the validity and applicability of the proposed technique. Similar procedure was presented by Han et al. [51] for the modal identification. Two approaches are adopted: the first one is based on the conjunction of HHT and the RDT and the other one is based on the EMD and stochastic subspace identification. The original signals from the field ambient vibration test of an arch bridge and a shaking table test of a reinforced concrete (RC) frame model are analyzed and modal parameters are identified for comparison. It is found that the both the approaches are capable of identification structural modal properties. Furthermore, Han et al. [52] also investigate the performance of a detection approach based on the EMD, RDT, and the Ibrahim time domain (ITD) approaches for the same two cases. Additionally, the HHT approach was also applied by $\mathrm{Xu}$ et al. [53] to identify the modal properties of a large-scale cable-stayed bridge.

More recently, He et al. [54] carried out the field monitoring and modal parameter identification of an existing railway bridge in China (see Figure 6(b)) by using the EMD based RDT approach. The identification result is compared to those from finite element analysis as well as from the experimental result identified with the peak-picking method. In addition, the modal frequencies of the bridge loaded with heavy trains are also identified and compared to the "empty" bridge. It is found that the EMD based RDT provides an effective and promising tool for modal parameter identification for large bridges and other structures. It is seen that the system identification process for the bridges and high-rise building is similar.

\section{Damage Detection}

\subsection{Detection on Common Damage Event}

4.1.1. Benchmark Building. The International Association for Structural Control and the Dynamics Committee of the ASCE Engineering Mechanics Division proposed to form task groups of SHM study, and a benchmark structure was established to compare the feasibility and validity of the various methods and techniques of SHM. Yang et al. [55, 56] and Lin et al. [57] conducted the damage identification of ASCE structural health monitoring benchmark building by using a technique based on the HHT for linear structures. The structural parameters, including the stiffness and damping, before and after damage are identified first and then the location and severity of the damage are assessed by a comparison. The made observations indicate that the accuracy of the HHT technique presented for identifying the structural damages is very plausible, and it represents a viable system identification and damage detection technique for linear structures. Furthermore, ASCE benchmark building is also taken as the example building by Liu et al. [58] to examine the feasibility and validity of the HHT method through comparative study on several damage scenarios. The results demonstrate that HHT method has the capability of recovering the actual signals' time-frequency feature and detecting and locating the actual structural damages.

4.1.2. Common Structures. Koh et al. [59] carried out the damage quantification of flexurally loaded RC slab using frequency response data. A one-way RC slab was subjected to short-duration concentrated impact load and its dynamic characteristics for the virgin and damaged conditions were studied using signal processing technique HHT. Salvino et al. [60] developed an approach based on EMD and HHT in 
conjunction with a wave-mechanics-based concept to detect adverse changes in a structure. Damage detection applications are investigated by using numerical simulations and a variety of laboratory experiments with simple structures. Huang et al. [61] proposed a HHT-based bridge structural health-monitoring method. This new method depends on a transient test load and simple data collection and enjoys many advantages: no a priori data required, simple data collection, minimum traffic disruption, and precise and nuance quantitative answers. The result of a case study is presented, which establishes the feasibility of this new approach for structural health monitoring. Wu et al. [62] developed a new method based on HHT to monitor the health of large civil structure in unknown excitation. Both Hilbert-Huang spectrum and marginal spectrum analysis based on HHT are utilized for damage assessment.

Dong et al. [63] proposed a method based on EMD and vector autoregressive moving average (VARMA) model for structural damage detection. The basic idea of the method is that the structural damages can be identified as the abrupt changes in energy distribution of structural responses at high frequencies. The Imperial County Services Building and the Van Nuys Hotel are taken as the benchmark structures to verify the effectiveness and sensitivity of the damage index in real environments. The damage detection of a transmission tower was conducted by Qu and Lian [64] through developing an approach based on HHT. EMD is used to decompose response signal that has occurred in the same position on transmission tower before and after damage. Shape factor is used to analyze the response signal of the structural IMFs. To contrast shape factor of the IMF of response signal that the structure is damaged before and after. Then it can judge the damage on the structure intuitively.

4.1.3. Composite Structures. Chen et al. $[65,66]$ developed a vibration-based approach to detect the damage of composite wingbox structures using improved HHT. The improved HHT approach is composed of HHT with wavelet packet transform and a simple but effective method for IMFs selection. The dynamic responses of intact wingbox and damaged wingbox are disposed using improved HHT and a feature index vector of structural damage; that is, the variation quantity of instantaneous energy, is constructed. The obtained results show that the proposed damage feature index vector is more sensitive to small damage than those in traditional signal processing. Esmaeel and Taheri [67] introduced an EMD based nondestructive damage detection methodology for detecting delamination damage in composite beams. The method uses the vibration signature of the structure, captured through piezoelectric sensors. The integrity of the methodology is established through both experimental and computational investigations. The method was successful in distinguishing lengthwise and through-thethickness locations of delamination, as well as the growth in delamination size.

4.2. Detection of Sudden Damage Event. The degradation of civil engineering structures due to harsh environment may lead to a sudden change of stiffness in a structure associated with the events such as weld fracture, column buckling, and brace breakage $[68,69]$. Such a sudden change of stiffness in a structure will cause a discontinuity in acceleration response time histories recorded in the vicinity of damage location at damage time instant. Since most of traditional vibrationbased damage detection methods operate with structural response data recorded before and after the occurrence of structural damage [70], they cannot be used to detect damage event on line and find out when the damage event occurs. To acquire a damage feature retaining damage time instant, the application of time-frequency data processing tool such as HHT for analyzing measurement data is necessary.

Hou et al. [71, 72] proposed a wavelet-based approach to identify the damage time instant and damage location of a simple structural model with breakage springs. The same idea for detecting sudden damage was adopted by Vincent et al. [22] and Yang et al. [25] but using EMD, to decompose the vibration signal to capture the signal discontinuity. Salvino and Pines [73] developed robust systems that can detect and locate progressive deterioration in structures or abrupt damage induced by extreme loading events in the field of structural health monitoring. Yang et al. [74] also detected the sudden damage event of ASEC structural health monitoring benchmark building. The structural damage detection was conducted based on HHT by using the two proposed approaches. The first method, based on the EMD, is intended to extract damage spikes due to a sudden change of structural stiffness from the measured data, thereby detecting the damage time instants and damage locations. The second method, based on EMD and Hilbert transform, is capable of detecting the damage time instants and determining the natural frequencies and damping ratios of the structure before and after damage. Numerical simulation carried out in their studies showed that EMD approach could also identify the damage time instant and damage location using the signal feature of damage spike. In addition to the abovementioned numerical studies, $\mathrm{Xu}$ and Chen [75] carried out experimental studies on the applicability of EMD for detecting structural damage caused by a sudden change of structural stiffness.

However, the reported method based on HHT may not be suitable for online structural health monitoring applications because it needs great computation effort. Additionally, quantization of the damage severity is still a challenging issue. To this end, Chen and $\mathrm{Xu}[76,77]$ proposed a new damage index to detect the damage time instant, location, and severity of a structure due to a sudden change of structural stiffness. The signal features due to sudden damage are firstly summarized and a new damage index, $\mathrm{DI}_{i}$, is defined to reflect the signal discontinuity due to sudden damage at the time instant $t_{i}$ :

$$
\begin{aligned}
\mathrm{DI}_{i} & =\left|\left(K_{i}-K_{i-1}\right)+\left(K_{i}-K_{i+1}\right)\right| \\
& =\left|2 K_{i}-K_{i-1}-K_{i+1}\right| \quad(k=2,3, \ldots, n-1),
\end{aligned}
$$

where $K_{i}$ is the slope of a certain dynamic response at time instant $i$. This damage index is computed in the time domain and it is an instantaneous index suitable for online structural health monitoring application. Chen and $\mathrm{Xu}$ theoretically proved that the damage index is proportional to the extent 


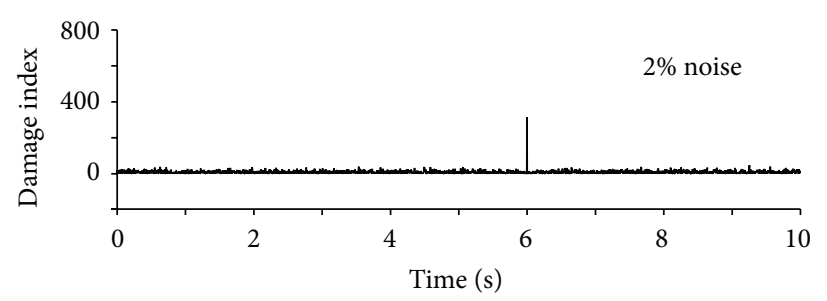

(a)

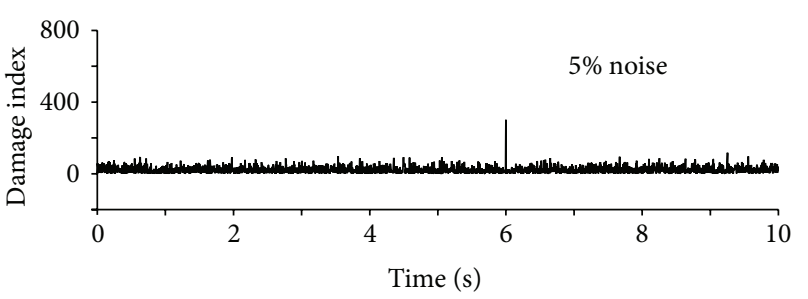

(b)

FIGURE 7: Damage detection with noise contamination subjected to seismic excitation.

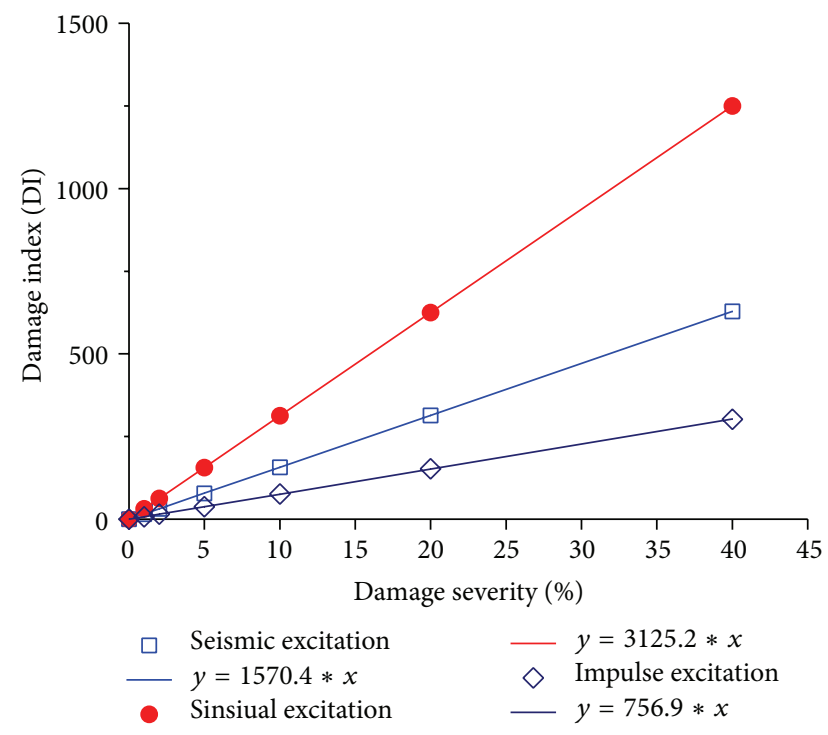

FIGURE 8: Relationship between damage index and damage severity.

of the sudden stiffness reduction. The proposed damage index is suitable for online structural health monitoring applications. It can also be used in conjunction with the EMD for damage detection without using the intermittency check. Numerical simulation using a five-story shear building under different types of excitation is executed to demonstrate the effectiveness and reliability of the proposed damage index and damage detection approach for the building with noise contamination (see Figure 7). The relation between the damage severity and the proposed damage index is linear as shown in Figure 8. Chen et al. [78, 79] also improved the proposed approach to detect the sudden damage events of a reticulated shell. The dynamic responses of the shell nodes were decomposed in both the global coordinate system (GCS) and the local coordinate system (LCS) of damaged members. Two detection schemes, based on the GCS and LCS, respectively, were developed and proved to be effective in sudden damage detection.

Most recently, Bao et al. [80] developed a multistage identification scheme for detecting damage in structures under ambient excitations by using an improved HHT method. Then a multistage damage detection scheme including the detection of damage occurrence, damage existence, damage location, and the estimation of damage severity was developed. Numerical and experimental studies of frame structures under ambient excitations were performed to investigate the validity of the approach.

4.3. Detection of Cracks and Flaws. It is well accepted that the ultrasonic signal analysis is one of the foremost nondestructive evaluation techniques for the detection of cracks and flaws. However, the complex and chaotic nature of raw time domain ultrasonic signals makes it very difficult for meaningful interpretation of the unprocessed time histories. The real challenge comes in extracting the damage information for large amounts of raw signals. To this end, time series approaches such as short-time Fourier transform (STFT), WT, Stockwell transform, HHT, and Winger-Wille have been widely adopted for the flaw detection.

4.3.1. Common Structures. Quek et al. [81] investigated the feasibility of the HHT as a signal processing tool for locating an anomaly, in the form of a crack, delamination, stiffness loss, or boundary in beams and plate, based on physically acquired propagating wave signals. The results indicate that crack and delamination in homogeneous beams can be located accurately and damage in a reinforced concrete slab can be identified if it has been previously loaded beyond first crack. A comprehensive methodology for locating and determining the extent of linear cracks in homogeneous plates based on the time-of-flight analysis of lamb wave propagation is proposed by Tua et al. [82]. Experimental results obtained using aluminum plates with through, half-through, and concealed cracks showed that the proposed method is feasible and accurate. The dynamic behaviour of a cantilever beam with a breathing crack was investigated by Douka and Hadjileontiadis [83] theoretically and experimentally. Both simulated and experimental response data are analysed by applying EMD and HT to reveal the physical process of crack breathing.

Lin et al. [84] developed a signal processing method for the impact-echo test based on the HHT. Numerical simulations and model tests show that the proposed method is promising in the detection of internal cracks in concrete even when the vibration and noise signals are strong. Yadav et al. [85] developed a method to extract damage sensitive features for crack detection by using flaw scattered ultrasonic signal. A steel channel section with several rivet holes has been considered as a physical problem to be analyzed to generate ultrasonic wave field data. The simulation has been 


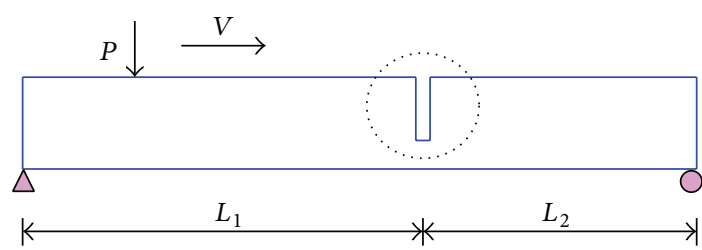

FIGURE 9: Simply supported beam with an open crack subjected to a moving load.

carried out by the finite element method for two cases: a steel plate with cracks extending from the rivet holes and an uncracked structure.

In addition, the structures with crack damages subjected to a moving load are also examined theoretically. Meredith et al. [86] investigated the possibility of applying EMD to the acceleration response of a beam with cracks subject to a moving load to detect damage. This method has been shown to be capable of detecting a crack of $10 \%$ of the beam depth in a signal generated at a velocity of $10 \mathrm{~m} / \mathrm{s}$ and corrupted with a signal to noise ratios of 5. Roveri and Carcaterra [87] developed a novel HHT based method for damage detection of bridge structures with cracks under a traveling load. The technique uses a single point measurement and is able to identify the presence and the location of the damage along the beam (see Figure 9). Theoretical as well as numerical results show that the identification is rather accurate and detection quality is not very sensitive to the crack depth and ambient noise, while they are sensibly affected by the damage location and by the speed of the moving load as well.

4.3.2. Pipelines. The structural damage detection and flaw characterization of pipelines have been investigated by many researchers to evaluate the integrity of a structure. Cheraghi et al. [88] assessed the vibration characteristics of plastic pipes using piezoelectric sensors with the aiding of HHT. A systematic experimental and analytical investigation was carried out to demonstrate the integrity of several methods commonly used to evaluate the damping of materials. An experimental investigation was also conducted and the results were compared and verified with finite element analysis, revealing good agreement. A new approach was developed by Kažys et al. [89] based on a combined application of nonlinear deconvolution and the HHT for ultrasonic detection of defects in strongly attenuating structures. The experimental investigations demonstrated a good performance of the proposed technique in the case of highly attenuating plastic pipes.

The HHT was combined with a local diagnostic approach by Rezaei and Taheri [90] to identify flaws in pipeline girth welds. This method is based on monitoring the free vibration signals of the pipe at its healthy and flawed states and processing the signals through the EMD. In the developed methodologies, the pipe's free vibration is monitored by piezoceramic sensors and a laser Doppler vibrometer. The effectiveness of the proposed techniques is demonstrated through a set of numerical and experimental studies on a steel pipe with a midspan girth weld. Results from both numerical and experimental studies reveal that in all damage cases the sensor located at the notch vicinity could successfully detect the notch and qualitatively predict its severity. The HHT approach was also adopted by Ghazali et al. [91] for the SHM of a pipeline system while attention was paid to the pipeline leaks and features. Both simulated and experimental pressure signals were used and analyzed by the HHT to evaluate the performance.

4.3.3. Special Structures. Chen et al. [92] proposed a vibration-based approach to detect crack damage for large structural systems by using the HHT. The proposed method has been numerically implemented on a composite wingbox and the examination of the results confirms that the identification method is very robust. Ramesh Babu et al. [93] investigated the possibility of applying HHT techniques for crack detection and monitoring when a rotor is passing through the critical speed. It has been found that HHT appears to be a better tool compared to FFT and continuous wavelet transform for crack detection in a transient rotor. Additionally, many detection approaches based on HHT and other time-frequency analytical methods have been proposed for the damage detection of structures with cracks and flaws, in particularly in the fields of mechanical engineering and aerospace engineering. Pavlopoulou et al. [94] illustrated the applicability of HHT on the postprocessing of guided ultrasonic waves for evaluating the condition of relatively complex structural health monitoring applications. Two case studies are presented to demonstrate the suitability of the techniques, namely, the damage monitoring of an aluminium repaired panel and the cure level monitoring of symmetric carbon fibre-epoxy composite laminates.

\subsection{Experiment and Field Testing}

4.4.1. Experiment on Sudden Damage. The detection of sudden stiffness reduction is performed through numerical simulation and the validity is not investigated by experiment. Therefore, $\mathrm{Xu}$ and Chen $[75,95]$ carried out experimental studies on the applicability of EMD for detecting structural damage caused by a sudden change of structural stiffness. A three-story shear building model was constructed and installed on a shaking table with two springs horizontally connected to the first floor of the building to provide additional structural stiffness. Structural damage was simulated by suddenly releasing two pretensioned springs either simultaneously or successively (see Figure 10). Various damage severities were produced using springs of different stiffness. A series of acceleration responses of free vibration, random vibration, and earthquake simulation were measured on the building with sudden stiffness changes as shown in Figure 11. The influence of damage severity, sampling frequency, and measured quantities on the performance of EMD for damage detection was also discussed.

4.4.2. Experiment on Common Damage. Liu et al. [96] proved the effectiveness and accuracy of HHT method for system identification and damage detection through a series of experiments. An MDOF structure model is established 


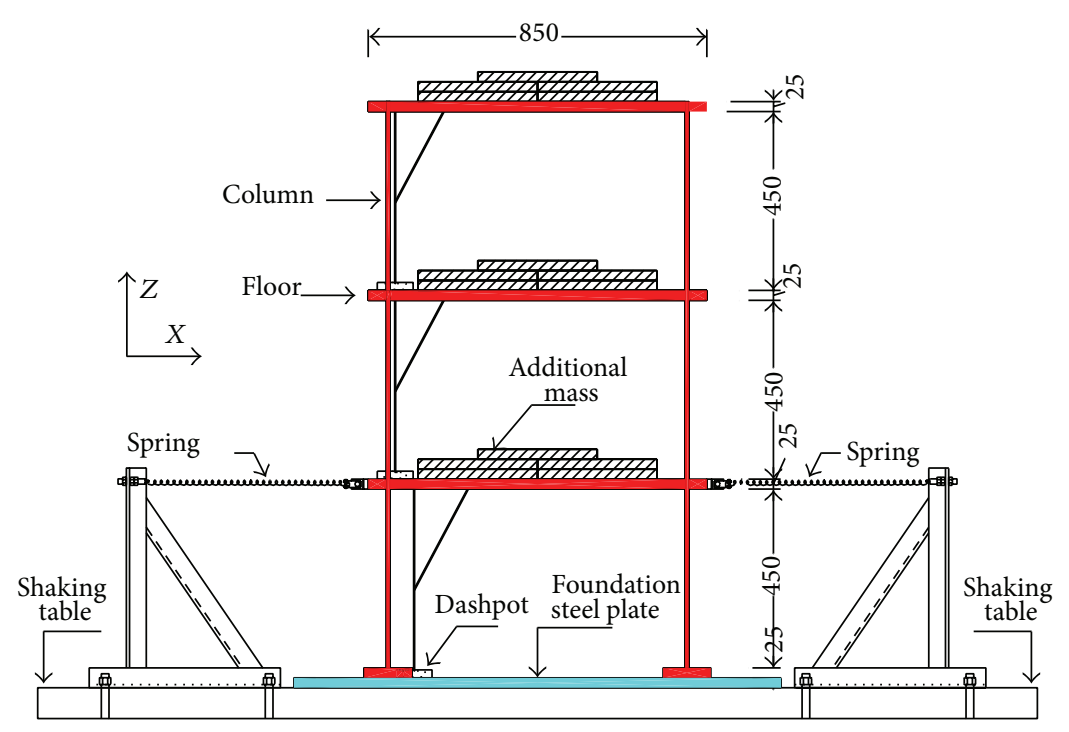

(a) Elevation

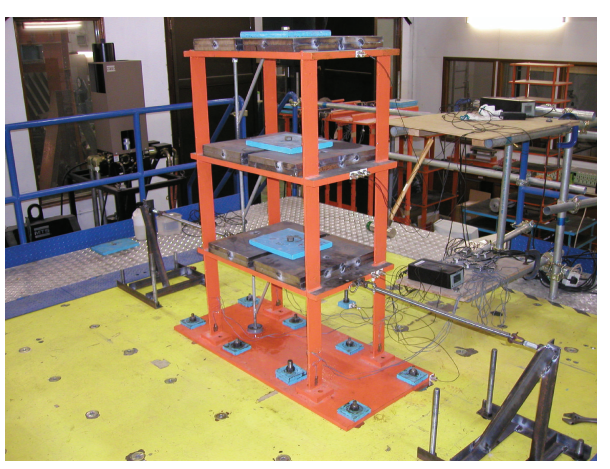

(b) Real model

Figure 10: Configuration of the building model (unit: $\mathrm{mm}$ ).

with modular members, and the columns can be replaced or removed to simulate damages of different location and severity under variable structural parameters. Based on a comparison of the stiffness of each story unit prior to and after damage, the damage location and severities can be identified. Pines and Salvino [97] discussed the application of the EMD to health monitoring of structures theoretically and experimentally. The EMD method is used to process timeseries data from a variety of 1D structures with and without structural damage. Results illustrate that the EMD method is a powerful signal processing tool that tracks unique features in the vibratory response of structures.

A new damage index, referred to as the EMD energy damage index, was developed by Rezaei and Taheri [98] to detect the damage in beams using EMD. Finite element simulation of a cantilevered steel beam with a transverse notch was analyzed and various notch sizes, located at different locations along the beam, were investigated. The effect of the boundary conditions on the EMD energy damage index was also experimentally studied. A damage detection index named the ratio of bandwidth is proposed by Chiou et al. [99] for structural damage detection. This index is highly correlated or approximately equal to the change of equivalent damping ratio for an intact structure incurring damage from strong ground motions. Based on an analysis of shaking table test data from benchmark models subjected to adjusted Kobe and El Centro earthquakes, the damage detection index is evaluated using the HHT and the FFT methods, respectively. Furthermore, Tang et al. [100] investigated the feasibility of detecting structural damage using a damage detection index, the ratio of equivalent damping ratio. The damage detection index is evaluated using the HHT and the FFT methods for the analysis of shaking table test data obtained for benchmark models.

Lin and Chu [101] utilized the HHT to characterize the acoustic emission (AE) signals released from the offshore structure model through experimental testing as shown in Figure 12. The AE signals from the cracks in the welded steel nodes of the offshore structure model are collected during the tensile testing in water. Instantaneous frequency and energy features based on local properties of the AE signals are then extracted using the HHT method. The results verify that the method based on HHT better characterizes the AE signals than the classical AE techniques. Similar approach based on HHT and AE is utilized by Hamdi et al. [102] to establish a procedure for understanding damage mechanisms within multilayered composite structures. The analysis is first applied to a set of known AE signals from well-controlled bending tests on unidirectional composite samples. Then, the analysis is applied to random $\mathrm{AE}$ signals collected from a static three-point bending test on a GFRP composite material. It is found that the HHT provides encouraging results for nonstationary AE signals features extraction.

Kunwar et al. [103] presented the health monitoring of an experimental bridge model using the HHT as shown in Figure 13. A $4 \times 1 \mathrm{~m}$ single span-bridge instrumented with 10 wireless sensor nodes is used for the study. Bridge vertical accelerations are measured as a wheel and axle is gently rolled across its length to simulate passing vehicles. The Hilbert spectrum for multiple runs, joint time-frequency analysis for individual runs, marginal Hilbert spectrum, and instantaneous phase were examined for the baseline bridge and the three damage cases. The results demonstrate that the method can detect and locate damage under transient vibration loads. Hsu et al. [104] proposed a damage detection index named as the ratio of bandwidth to detect damage of a steel structure with the occurrence of the initial stiffness reduction through experiment. The results of this study also demonstrate that the HHT is a powerful method for analyzing the acceleration data for steel structures with initial damage from earthquakes. 


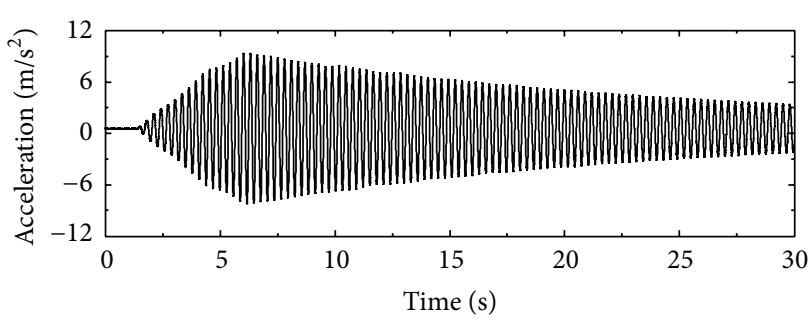

(a) Response of the 3rd floor

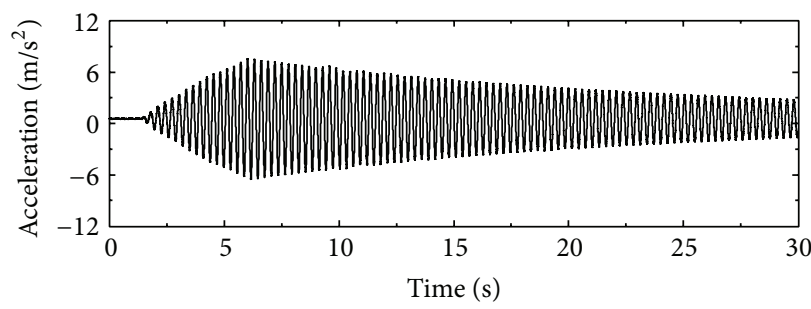

(b) Response of the 2nd floor

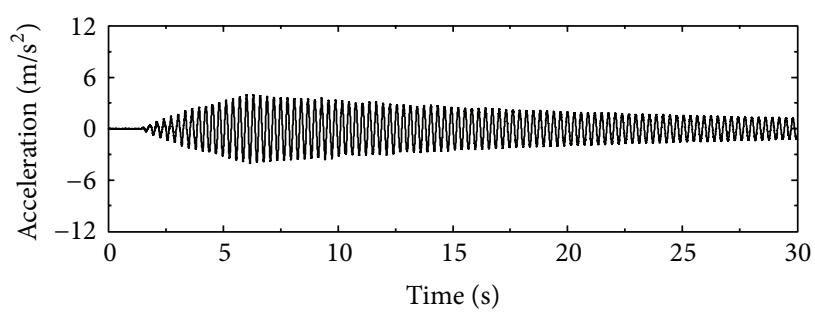

(c) Response of the 1st floor

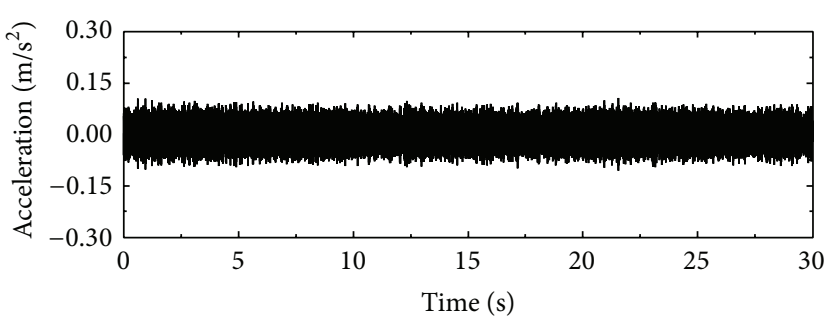

(d) IMF1 of 3rd floor's response

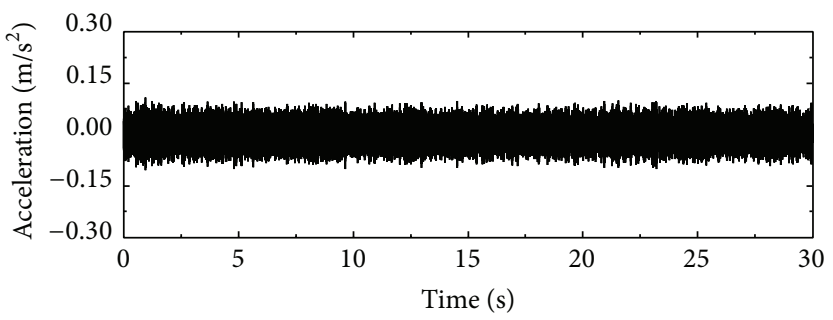

(e) IMF1 of 2nd floor's response

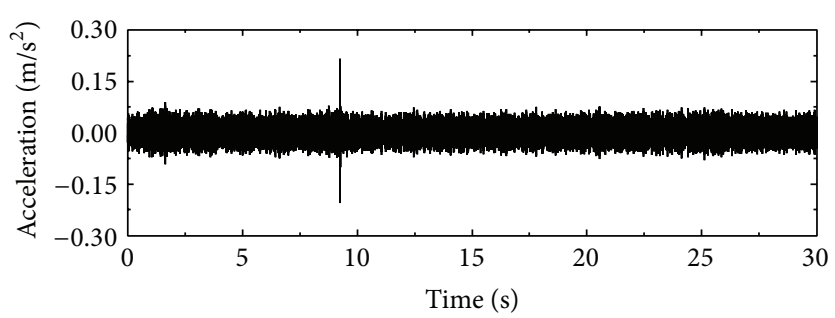

(f) IMF1 of 1st floor's response

FIGURE 11: Damage time instant and location identification.

4.4.3. Field Testing. Compared to the theoretical and experimental investigation, the studies on the performance of HHT based damage detection approach through field measurement are quite limited. Zhang et al. $[105,106]$ carried out the dynamic condition assessment on a bridge substructure with HHT. Their study involved modal vibration tests combined with the HHT to analyze previous recordings of controlled field vibration tests of one concrete pile substructure of the Trinity river relief bridge number 4 in Texas in its intact, minor- and severe-damage states as shown in Figure 14. Piles were excavated and broken to simulate flood and earthquake damage to a bridge substructure. The HHT algorithm is unique in that it reveals the quantitative difference in instantaneous frequency of sound and damaged structures, consistent with the damage states and with what a simple structural model predicts. This approach differs from traditional modal vibration analyses in that a short-lived shift downward in resonant frequency can be seen in the HHT from a damaged member, but this is often lost in the averaging effect of a modal vibration analysis. They also discussed the characteristics of an HHT-based approach in the structural health monitoring. Liu et al. [107] investigated the characteristics of aging bridges by comparison with their structural properties under ambient vibration tests which were firstly performed on a damaged bridge and the collected responses were analyzed by using HHT to perform a structural health assessment to evaluate the extent of damage.

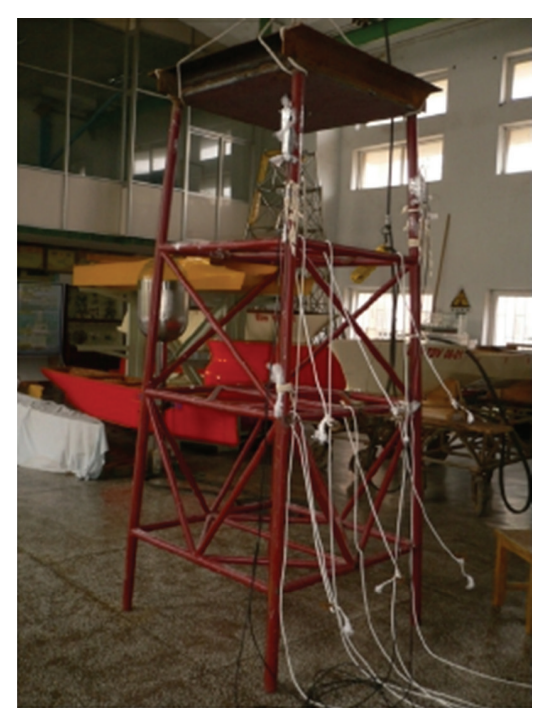

FIGURE 12: Testing model of an offshore structure.

\section{Performance Assessment in SHM}

\subsection{Performance Assessment in Wind Engineering}

5.1.1. Wind Loading. $\mathrm{Xu}$ and Chen $[108,109]$ proposed a procedure to characterize the nonstationary wind speed 


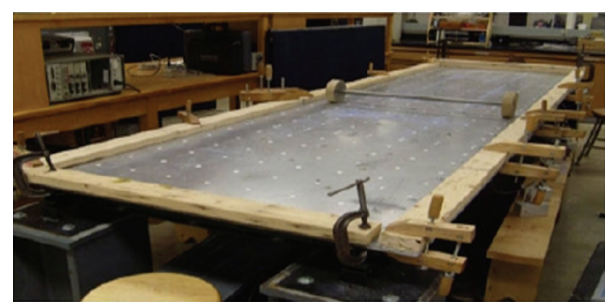

(a) Experimental bridge model

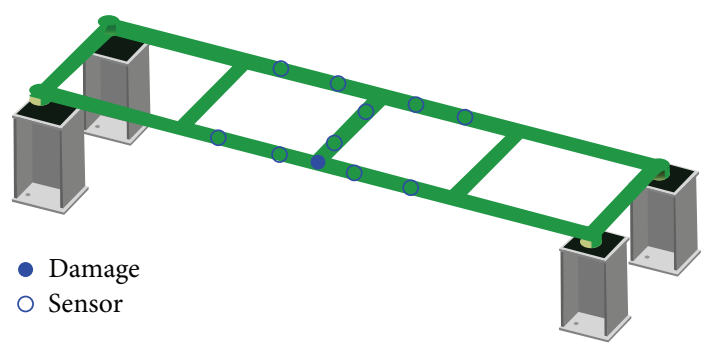

(b) Damage and sensor locations

FIGURE 13: Experimental arrangement of the example bridge.

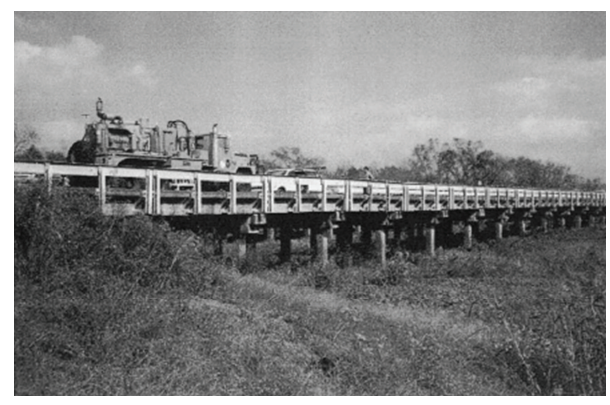

Figure 14: Example bridge in Texas.

using EMD. The nonstationary wind speed was modeled as a deterministic time-varying mean wind speed component plus a stationary random process for the fluctuating wind speed component:

$$
U(t)=\bar{U}(t)+u(t)
$$

where $\bar{U}(t)$ is the deterministic time-varying mean wind speed reflecting the temporal trend of wind speed and $u(t)$ is the fluctuating component of wind speed that can be modeled as a zero-mean stationary process. This model simply allows the mean wind speed to vary over time in an arbitrary fashion, providing a great flexibility for considering the variation of mean wind speed with time.

The proposed approach is then applied to the wind data recorded by the anemometers installed in the Tsing Ma Suspension Bridge during Typhoon Victor to find its time-varying mean wind speed, probability distribution of fluctuating wind speed, wind spectrum, turbulence intensity, and gust factor (see Figure 15). In addition, they also investigated the typhoon-induced nonstationary wind speed for tall buildings in the same way. The proposed approach was applied to the wind data recorded at the top of the Di Wang building during Typhoon York. Similar works are carried out by Li et al. [110] to investigate the time-frequency properties of typhoon effects on the same supertall structure, the Di Wang Building. The probability density and power spectral density of fluctuating wind speed were obtained by traditional methods and were further analyzed by considering timevarying mean values of the measured data via the EMD method. In addition, $\mathrm{Li}$ and $\mathrm{Wu}$ [111] also studied the wind effects on a $391 \mathrm{~m}$ supertall RC building in Guangzhou during

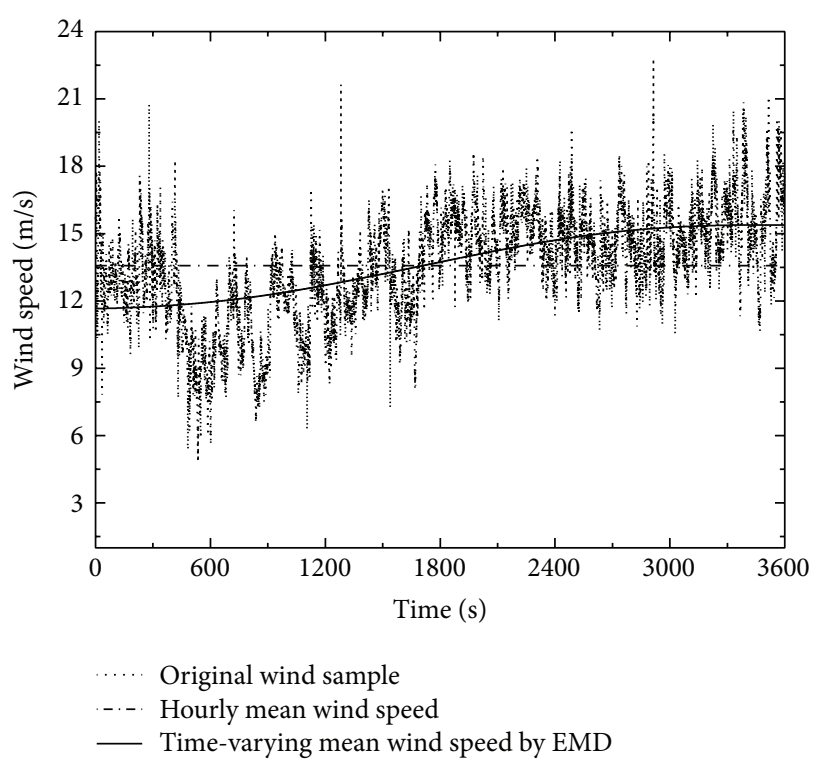

FIGURE 15: Time varying and hourly mean wind speeds (WITJS01 23:00-24:00).

typhoon Damrey in 2005. It was testified that the HHT method is a promising tool for the time-frequency analysis of random signal and can serve as a flexible and effective tool for analyzing field data of wind speed and wind-induced response with non-stationary features.

Tian et al. [112] studied the statistical spectrum model of wind velocity at Beijing meteorological tower. The wind velocity spectra are analyzed using HHT and FFT, respectively. It was concluded that the HHT spectrum describes elaborately and accurately the spectrum values in the low frequencies and the fitted wind velocity model provides a reference for reconstructing the near-ground wind field of Beijing city in wind tunnel test and for numerical simulation. Hsieh and Dai [113] analyzed the offshore islands wind characteristics in Taiwan by using HHT. The daily wind data for 40 years of three weather stations were investigated. The results of rolling average analysis, FFT and HHT analyses were presented to show the wind characteristics under various time-scale variations. Guo et al. [114] carried out the multistep forecasting for wind speed using a modified EMD-based feedforward neural network (FNN) model. The prediction 
results of the modeled IMFs and residual series are summed to formulate an ensemble forecast for the original wind speed series. The made observations indicated that the developed model shows the best accuracy compared with basic FNN and unmodified EMD-based FNN through multistep forecasting the mean monthly and daily wind speed.

5.1.2. Wind Induced Responses. Ma et al. [115] conducted the time-frequency analysis of nonlinear buffeting responses of a long-span bridge using the HHT. The time-frequency of empirical mode component in HHT transform is compared with the bridge natural frequency. The analysis result shows that the nonlinear buffeting responses of a long-span bridge present nonstationary properties and HHT is obviously better than FT in the identification of the frequency spectrum of buffeting responses. The aerodynamic damping properties on Sorok Bridge, a suspension bridge in Korea, were estimated by Park et al. [116] by using the HHT in comparison with the extended Kalman filter. Some correlation of wind speed, aerodynamic damping, and structural damping was investigated. It was found that pure structural damping ratio could be estimated using ambient vibration signals under various wind speeds. However, it was still hard to distinguish structural damping and aerodynamic damping from appearance damping only using appearance damping and wind components.

Zhang et al. [117] proposed a frequency modulated EMD method to track the variations in the modal parameters of a multi-DOF bridge-air system. Wind tunnel testing data of a partially streamlined box girder sectional model of a suspension bridge was processed subsequently with the proposed method. Instantaneous frequencies and damping ratios of the aeroelastic system during the free decay vibration were realized. Nonlinearity in the transient aeroelastic vibration was identified. Most recently, Yi et al. [118] examined dynamic characteristics and wind-induced responses of a $420 \mathrm{~m}$ high supertall building in Hong Kong during strong typhoons. The field data such as wind speed, wind direction, acceleration, and displacement responses were simultaneously and continuously recorded from an installed monitoring system. The multipath effects are extracted by a combination of EMD and wavelet method and then are removed by a high pass finite impulsive response digital filter to improve the performance of the GPS. The resonant and background responses of the supertall building as well as their contributions to the total displacements are investigated.

\subsection{Performance Assessment in Earthquake Engineering. Fea-} ture extraction from seismic accelerograms is a key issue in characterization of earthquake damage in structures. Up to now, a number of effective classical parameters such as peak ground acceleration and intensity have been proposed for analyzing the earthquake motion records. The HHT is a novel signal analysis method in seismic exploration, which can express the intrinsic essence using simple and understandable algorithm. In earthquake engineering, some recent approaches proposed the use of HHT and showed that it is able to extract more representative characteristics than the traditional signal processing methods.
5.2.1. Earthquake Excitation. Zhang [119] used the HHT to analyze ground acceleration recordings and then demonstrated the role in studies of seismology and earthquake engineering via the 1994 Northridge and 1999 Kocaeli Turkey earthquakes. In particular, the features of HHT based ground motion correlated to the motion's damage potential to civil structures were examined. Furthermore, Zhang et al. [120, 121] examined the rationale of HHT for analyzing dynamic and earthquake motion recordings in studies of seismology and engineering. The analysis of the two recordings indicated that the HHT method is able to extract some motion characteristics useful in studies of seismology and engineering, which might not be exposed effectively and efficiently by Fourier data processing technique. The study illustrated that the HHT based Hilbert spectra are able to reveal the temporal-frequency energy distribution for motion recordings precisely and clearly. Liang et al. [122] presented a rigorous derivation of a previously known formula for simulation of one-dimensional, univariate, nonstationary stochastic processes. Three methods are developed to estimate the evolutionary power spectral density function (PSDF) of a given time-history data by means of the STFT, the WT, and the HHT. A comparison of the PSDF of the well-known El Centro earthquake record estimated by these methods shows that the STFT and the WT give similar results, whereas the HHT gives more concentrated energy at certain frequencies. Yinfeng et al. [123] analyzed earthquake ground motions using an improved HHT approach by proposing a timevarying vector autoregressive moving average model based method to calculate the instantaneous frequencies of the IMFs. The analysis of the length of day dataset and the ground motion record El Centro (1940, NS component) indicated that the proposed method offers advantages in frequency resolution and produces more physically meaningful and readable Hilbert spectrum than the original HHT method, STFT, and WT.

Ni et al. [124] proposed a new modification method to generate a modified time-history compatible with the target design spectrum based on an actual earthquake record by using HHT. The compatible time-history was obtained by solving an optimization problem to minimize the difference between the response spectrum of the modified time-history and the target design spectrum. The HHT is used by Chen et al. [125] to identify earthquake signals from groundwater level records. The results indicate that the application of the HHT can improve understanding of automatic detection of the coseismic signals from the groundwater level. Wang et al. [126] compared the applications of EMD and ensemble empirical mode decomposition (EEMD) on time-frequency analysis of seismic signal. It is found that EEMD solves the mode mixing problem by adding a white noise to the original signal. The synthetic signal example reveals the remarkable ability of EEMD to decompose the signal into different IMFs and analyze the time-frequency distribution of the seismic signal. Ni et al. [127] proposed a new approach to generate spectrum-compatible earthquake ground motions considering intrinsic spectral variability using HHT. The spectrum compatible earthquake ground motions are generated by using HHT and solving related optimization problems. 
The generation procedure preserves the nonstationary characteristics of seed actual earthquake records and ensures the intrinsic aleatory variability of real ground motions for a given scenario earthquake.

5.2.2. Seismic Effect. Lee et al. [128] explored the vibration mechanism of a bridge at both global and local behavior. They proposed a combination of EMD, HHT, and a nonlinear parametric model as an identification methodology. The approach was successful in identifying abnormal signals indicating the structural condition of the bridge decks based on the time-frequency spectrum. Zhang [129] proposed a recordingbased approach to characterize and quantify earthquakeinduced site nonlinearity, exemplified as soil nonlinearity and/or liquefaction. With the use of the 2001 Nisqually earthquake recordings, this study shows that the proposed approach is effective in characterizing site nonlinearity and quantifying the influences in seismic ground responses. Alvanitopoulos et al. [130] studied crucial characteristic seismic parameters which provide information pertinent to the damage indicators of the structures. The first proposed parameter is the maximum amplitude and the second is the mean amplitude. Results indicate the high correlation of the new seismic parameters with the damage indices and confirm that HHT is a promising tool for extracting information to characterize seismic damage in structures. The HHT was successfully used by Wei et al. [131] to characterize the seismic responses of soil-quay wall systems using measured data in a series of geotechnical centrifuge shaking-table tests. It was found that the predominant instantaneous frequency at any given instant provides a superior indicator for characterizing the occurrence of liquefaction and the time-varying soil dynamic property.

5.3. Other Assessment Issues in SHM. Advanced signal processing techniques have been long introduced and widely used in structural health monitoring. The analysis and extraction of the appropriate signal's features in structural health monitoring applications is one of the major challenges on which the robustness of the designed systems relies. Many strategies have been developed in the past, which utilise the identification of amplitude-based parameters for the evaluation of structural integrity. However, these parameters usually require a baseline reference, which might be extensively affected by noise, environmental or mounting conditions. Therefore, the signal processing in SHM based on HHT has attracted more and more attention across the world.

Huang [132] reviewed the methods and many applications for nonsteady and nonlinear data analysis by using HHT. Qin et al. [133] studied the law of HHT and the characteristic of the IMFs of any signal with white noise and then developed a new method to remove white noise based on EMD. The feasibility of the HHT and the validity of the EMD based noise removing method were investigated through several examples. Wang et al. [134] applied HHT to decompose measured strain responses of a bridge into an oscillation component and a trend component. Simulation analysis results of a steel truss bridge show that the trend component of the strain response corresponds to the static effect caused by the loads, while the oscillation component is relative to the dynamic effect. Similar operation was conducted by $\mathrm{Hu}$ et al. [135] to analyze the vibration signal based on HHT.

In addition, the HHT can be revised or improved for vibration-based signal and data processing. Peng et al. [136] proposed an improved HHT method to analyze the vibration signal by using wavelet packet transform and a screening process. Both simulated and experimental vibration signals of having a rotary system with the fault of rubbing occurred have proven that the improved HHT does show the rubbing symptoms more clear and accurate than the original HHT. A revised HHT is proposed by Xun and Yan [137] to analyze vibration signals of a deployable structure in order to overcome shortcomings of the traditional HHT, such as the end swings problem and the undesired IMFs at the lowfrequency range. The results show that the revised HHT method is efficient for nonlinear and nonstationary vibration signal analysis. Lin [138] proposed an improved HHT for the modal evaluation of structural systems or signals. A well-designed bandpass filter is used as preprocessing to separate and determine each mode of the signal for solving the inherent mode-mixing problem in HHT. A screening process is then applied to remove undesired IMFs derived from the EMD of the signal's mode. Numerical results prove the efficiency of the proposed approach. Furthermore, Lin [139] presented a hybrid algorithm based on EEMD and EMD for multimode signal processing. A simulated twomode signal was tested to demonstrate the efficiency and robustness of the approach, showing average relative errors all equal to $1.46 \%$ for various noise levels added to the signal. The developed approach was also applied to a real bridge structure, showing more reliable results than the pure EMD.

Bridges are subjected to periodic environmental thermal effects induced by solar radiation and ambient air temperature. Excessive movement and stress induced by thermal loadings may damage the bridge $[47,48]$. Most recently, Chen et al. [140] carried out the condition assessment on thermal effects of the Tsing Ma Suspension Bridge based on SHM oriented model by using HHT in conjunction with spectral analysis. A new signal processing approach is proposed to process the measured data, such as strain, temperature, displacement, and acceleration, so as to extract the static, dynamic, and noise signal components for structural performance assessment. The responses of the bridge can be decomposed firstly to reconstruct the noise component $x_{\text {noise }}(t)$, dynamic component $x_{\text {dyn }}(t)$, and static component $x_{\text {static }}(t)$, respectively, with the aid of spectral analysis:

$$
\begin{gathered}
x_{\text {noise }}(t)=\sum_{j=1}^{m} c_{j}(t), \\
x_{\text {dyn }}(t)=\sum_{j=m+1}^{n-1} c_{j}(t), \\
x_{\text {static }}(t)=c_{n}(t)+r_{n}(t),
\end{gathered}
$$

where $n$ is the number of all the IMFs and $m$ is the number of noise IMF components. If the absolute mean value of 


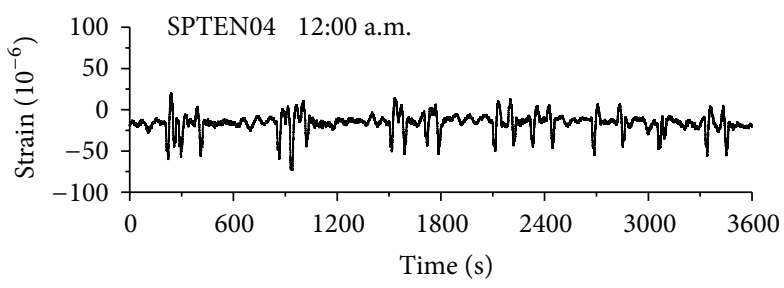

(a) Original axial strain

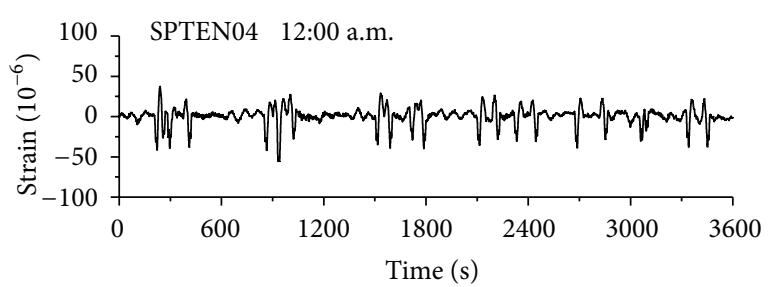

(b) Induced by dynamic traffics

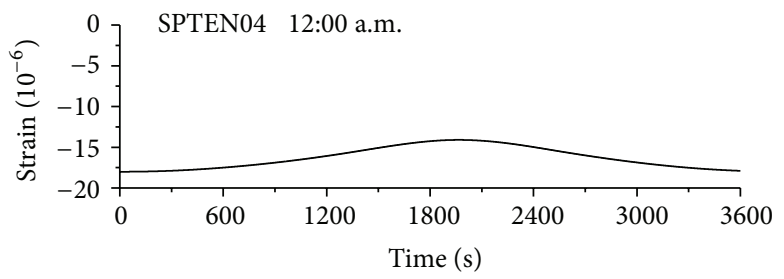

(c) Induced by temperature

FIgURE 16: Time histories of axial strain between 12:00 a.m. and 13:00 p.m.

a particular IMF is quite small, this IMF can be regarded as noise component:

$$
\operatorname{abs}\left(\operatorname{mean}\left(c_{j}(t)\right)\right)<\varepsilon_{m},
$$

where abs() means to take the absolute value and $\varepsilon_{m}$ is the threshold value of absolute mean value of a particular IMF component. It is seen from Figure 16 that the original axial strain responses are decomposed into responses induced by traffics and temperature, respectively.

\section{Concluding Remarks}

An overview was presented in this paper for developments of the HHT based approach in SHM of civil structures with special emphasis laid upon the system identification and damage detection. The HHT provides new insights into the nonstationary and nonlinear signals. Research activity going on around the world in terms of development and implementation of this technology in SHM of civil engineering structures was reviewed. The application of HHT in the system identification, damage detection, and performance assessment of SHM was presented, respectively. Compared with the conventional monitoring techniques in the frequency domain and the time domain, HHT based techniques not only provide alternative tools for monitoring structural performance but also have the distinguished superiority in exploring time-frequency properties of the structural responses. It is addressed in this review that HHT based techniques are promising for the SHM in comparison with traditional techniques. The development of HHT is not over yet. A more rigorous mathematical foundation for the general adaptive methods for data analysis is required and the end effects of HHT must be improved as well. In addition, there are still difficulties in the practical application of HHT based techniques for the SHM of civil engineering structures. The main challenges and future development trends are as follows.
(1) From the view, it can be seen that recently there have been innovative applications and major improvement to HHT. These improvements have spread to general analytical approaches as well as combination applications of the HHT. The HHT can be combined with other intelligence algorithms, like artificial neural network, genetic algorithm, and so forth, to form more powerful signal processing tools for analyzing structural monitoring information. Thus, the development and application of the HHT in conjunction with computational intelligence for SHM are necessary.

(2) The HHT is considered as a promising and powerful approach in the SHM, which is commonly compared with other signal processing tools in the frequency domain, time domain, and time-frequency domain, such as FFT, STFT, and WT. Comparative studies of HHT, FFT, and wavelet techniques have been addressed, but more research is needed to be conducted for determining which of these approaches is more applicable than the other in a certain issue of the SHM.

(3) The application of HHT demonstrates that the decomposition is subject to the limitation of being defined by an algorithm, and therefore it does not admit an analytical formulation that would allow for a theoretical analysis and performance assessment. The intermittency frequency as an additional criterion might not always guarantee the final expected results, since choosing the intermittency frequency is a subjective task. Therefore, how to reduce or eliminate the subjective effects of HHT based approaches on the quality of the system identification and damage detection should be further studied.

(4) Nowadays, a new approach referred to as bidimensional HHT is developed and employed for processing multidimensional signals. Nunes and coworkers [141] 
developed a method for analyzing two-dimensional (2D) time series which was used for textural analysis. Linderhed [142] proposed a 2D EMD and presented a coding scheme for image compression purposes. The results indicate that the $2 \mathrm{D}$ HHT outperforms traditional wavelet and Fourier analysis. Recently, the image processing techniques are widely adopted in the SHM. Therefore, it is important to develop new detection approaches and carry out the monitoring and evaluation using image analysis with the aid of the 2D HHT.

(5) It is reported theoretically and experimentally that the result generated by the HHT has its deficiency. The EMD may generate undesirable IMFs at the low-frequency region to induce misunderstanding of the SHM result. The first obtained IMF may cover a very wide frequency range such that the properties of monocomponent cannot be achieved, which maybe an important issue in the identification of higher modal parameters and sudden damage detection with noise contamination. In addition, the EMD cannot separate signals that contain low-energy components, which makes it difficult to separate low frequency signal of structural monitoring responses induced by temperature and ambient wind. These disadvantages may induce the misidentification and misunderstanding of structural condition assessment, which deserves further investigation in the further.

Although there still exist some limitations, the benefits of the HHT technology far outweigh the problems of not using them. This is evident by the tremendous amount of contributions from the scientific community for introducing this technology into the mainstream of civil engineering. Thus, the manifestation of the HHT technology in civil structures is warmly expected.

\section{Conflict of Interests}

The authors declare that there is no conflict of interests regarding the publication of this paper.

\section{Acknowledgments}

The authors are grateful for the financial support from the technological project of the Chinese Southern Power Grid Co., Ltd. (Grant K-GD2013-0783), the National Natural Science Foundation of China (Grant 51178366), the Fundamental Research Funds for the Central Universities (WUT 2013-II-015), and the Fok Ying-Tong Education Foundation (Grant 131072).

\section{References}

[1] C. R. Farrar, S. W. Doebling, and D. A. Nix, "Vibration-based structural damage identification," Philosophical Transactions of the Royal Society A: Mathematical, Physical and Engineering Sciences, vol. 359, no. 1778, pp. 131-149, 2001.
[2] B. Chen, Y. L. Xu, and W. L. Qu, "Evaluation of atmospheric corrosion damage to steel space structures in coastal areas," International Journal of Solids and Structures, vol. 42, no. 16-17, pp. 4673-4694, 2005.

[3] B. Chen, Y. L. Xu, and X. Zhao, "Integrated vibration control and health monitoring of building structures: a time-domain approach," Smart Structures and Systems, vol. 6, no. 7, pp. 811833, 2010.

[4] A. E. Aktan, C. J. Tsikos, F. N. Catbas, K. Grimmelsman, and R. Barrish, "Challenges and opportunities in bridge health monitoring," in Proceedings of the 2nd International Workshopon Structural Health Monitoring, pp. 461-473, Stanford University, Palo Alto, Calif, USA, 1999.

[5] A. E. Aktan, F. N. Catbas, K. A. Grimmelsman, and C. J. Tsikos, "Issues in infrastructure health monitoring for management," Journal of Engineering Mechanics, vol. 126, no. 7, pp. 711-724, 2000.

[6] T. H. Yi, H. N. Li, and H. M. Sun, "Multi-stage structural damage diagnosis method based on energy-damage theory," Smart Structures and Systems, vol. 12, no. 3-4, pp. 345-361, 2013.

[7] S. W. Doebling, C. R. Farrar, M. B. Prime, and D. W. Shevitz, "Damage identification and health monitoring of structural and mechanical systems from changes in their vibration characteristics: a literature review," Los Alamos National Laboratory Report LA-13070-MS, 1996.

[8] S. W. Doebling, C. R. Farrar, and M. B. Prime, "A summary review of vibration-based damage identification methods," Shock and Vibration Digest, vol. 30, no. 2, pp. 91-105, 1998.

[9] H. Sohn, C. R. Farrar, F. M. Hemez, D. D. Shunk, D. W. Stinemates, and B. R. Nadler, "A review of structural health monitoring literature: 1996-2001," Los Alamos National Laboratory Report LA-13976-MS, 2003.

[10] J. E. Mottershead and M. I. Friswell, "Model updating in structural dynamics: a survey," Journal of Sound and Vibration, vol. 167, no. 2, pp. 347-375, 1993.

[11] K. Gurley and A. Kareem, "Applications of wavelet transforms in earthquake, wind and ocean engineering," Engineering Structures, vol. 21, no. 2, pp. 149-167, 1999.

[12] Y. L. Xu and B. Chen, "Integrated vibration control and health monitoring of building structures using semi-active friction dampers. Part I: methodology," Engineering Structures, vol. 30, no. 7, pp. 1789-1801, 2008.

[13] B. Chen and Y. L. Xu, "Integrated vibration control and health monitoring of building structures using semi-active friction dampers. Part II: numerical investigation," Engineering Structures, vol. 30, no. 3, pp. 573-587, 2008.

[14] D. J. Ewins, Modal Testing: Theory and Practice, John Wiley, New York, NY, USA, 2nd edition, 2000.

[15] H. Li, T. Yi, M. Gu, and L. Huo, "Evaluation of earthquakeinduced structural damages by wavelet transform," Progress in Natural Science, vol. 19, no. 4, pp. 461-470, 2009.

[16] T. H. Yi, H. N. Li, and X. Y. Zhao, "Noise smoothing for structural vibration test signals using an improved wavelet thresholding technique," Sensors, vol. 12, no. 8, pp. 11205-11220, 2012.

[17] T. H. Yi, H. N. Li, and M. Gu, "Wavelet based multi-step filtering method for bridge health monitoring using GPS and accelerometer," Smart Structures and Systems, vol. 11, no. 4, pp. 331-348, 2013.

[18] N. E. Huang, S. R. Long, and Z. Shen, "The mechanism for frequency down shift in nonlinear wave evolution," Advances in Applied Mechanics, vol. 32, pp. 59-111, 1996. 
[19] N. E. Huang, Z. Shen, S. R. Long et al., "The empirical mode decomposition and the Hilbert spectrum for nonlinear and non-stationary time series analysis," Proceedings of the Royal Society of London A: Mathematical, Physical and Engineering Sciences, vol. 454, no. 1971, pp. 903-995, 1998.

[20] N. E. Huang, Z. Shen, and S. R. Long, "A new view of nonlinear water waves: the Hilbert spectrum," in Annual Review of Fluid Mechanics, vol. 31, pp. 417-457, 1999.

[21] N. E. Huang, The Hilbert-Huang Transform in Engineering, Taylor and Francis Group, New York, NY, USA, 2005.

[22] B. Vincent, J. Hu, and Z. Hou, "Damage detection using empirical mode decomposition and a comparison with wavelet analysis," in Proceedings of 2nd International Workshop on Structural Health Monitoring, pp. 891-900, Stanford Univeristy, Stanford, Calif, USA, 1999.

[23] J. N. Yang and Y. Lei, "Identification of natural frequencies and damping ratios of linear structures via Hilbert transform and empirical mode decomposition," in Proceedings of the International Conference on Intelligent Systems and Control, pp. 310-315, IASTED/Acta Press, Anaheim, Calif, USA, 1999.

[24] J. N. Yang and Y. Lei, "System identification of linear structures using Hilbert transform and empirical mode decomposition," in Proceedings of 18th International Modal Analysis Conference (IMAC '00), vol. 1, pp. 213-219, San Antonio, Tex, USA, 2000.

[25] J. N. Yang, Y. Lei, and N. E. Huang, "Damage identification of civil engineering structures using Hilbert-Huang transform," in Proceedings 3rd International Workshop on Structural Health Monitoring, pp. 544-553, Stanford, Calif, USA, 2001.

[26] J. S. Bendat and A. G. Piersol, Random Data: Analysis and Measurement Procedures, Wiley \& Sons, New York, NY, USA, 3rd edition, 2000.

[27] J. N. Yang, Y. Lei, S. Pan, and N. Huang, "System identification of linear structures based on Hilbert-Huang spectral analysis. Part 1: normal modes," Earthquake Engineering and Structural Dynamics, vol. 32, no. 9, pp. 1443-1467, 2003.

[28] J. N. Yang, Y. Lei, S. Lin, and N. Huang, "Identification of natural frequencies and dampings of in situ tall buildings using ambient wind vibration data," Journal of Engineering Mechanics, vol. 130, no. 5, pp. 570-577, 2004.

[29] C. W. Poon and C. C. Chang, "Identification of nonlinear normal modes of structures using the Empirical Mode Decomposition method," in Smart Structures and Materials 2005: Sensors and Smart Structures Technologies for Civil, Mechanical, and Aerospace Systems, Proceedings os SPIE, pp. 881-891, March 2005.

[30] C. W. Poon and C. C. Chang, "Identification of modal responses of hysteretic structures using Hilbert-Huang Method," in Smart Structures and Materials 2006: Sensors and Smart Structures Technologies for Civil, Mechanical, and Aerospace Systems, Proceedings of SPIE, article 61743C, Bellingham, Wash, USA, 2006.

[31] D. Cui, K. Xin, and Q. Qi, "Structural modal analysis based on HHT and Butterworth filter," in Advanced Materials Research, vol. 255-260, pp. 1836-1840, Trans Tech Publications Ltd., Zurich, Switzerland, 2011.

[32] B. Yan and A. Miyamoto, "A comparative study of modal parameter identification based on wavelet and Hilbert-Huang transforms," Computer-Aided Civil and Infrastructure Engineering, vol. 21, no. 1, pp. 9-23, 2006.

[33] J. N. Yang, Y. Lei, S. Pan, and N. Huang, "System identification of linear structures based on Hilbert-Huang spectral analysis. Part 2: complex modes," Earthquake Engineering and Structural Dynamics, vol. 32, no. 10, pp. 1533-1554, 2003.
[34] J. Chen, "Hilbert-Huang transform for damping ratio identification of structures with closely spaced modes of vibration," in Proceedings of the International Conference on Advances in Building Technology, vol. 1-2, pp. 1107-1114, December 2002.

[35] J. Chen and Y. L. Xu, "Identification of modal damping ratios of structures with closely spaced modal frequencies," Structural Engineering and Mechanics, vol. 14, no. 4, pp. 417-434, 2002.

[36] M. Zheng, F. Shen, Y. Dou, and X. Yan, "Modal identification based on Hilbert-Huang transform of structural response with SVD preprocessing," Acta Mechanica Sinica, vol. 25, no. 6, pp. 883-888, 2009.

[37] Z. X. Li and C. X. Bao, "An adaptive algorithm for frequency identification based on Hilbert-Huang transform," in Proceedings of the 2nd International Conference on Structural Condition Assessment, Monitoring and Improvement, vol. 1-2, pp. 875-887, 2007.

[38] K. C. G. Ong, Z. Wang, and M. Maalej, "Adaptive magnitude spectrum algorithm for Hilbert-Huang transform based frequency identification," Engineering Structures, vol. 30, no. 1, pp. 33-41, 2008.

[39] O. Bahar and S. Ramezani, "Enhanced Hilbert-Huang transform and its application to modal identification," Structural Design of Tall and Special Buildings, vol. 23, no. 4, pp. 239-253, 2012.

[40] N. Wu, C. Liu, Y. Guo, and J. Zhang, "On-board computing for structural health monitoring with smart wireless sensors by modal identification using Hilbert-huang transform," Mathematical Problems in Engineering, vol. 2013, Article ID 509129, 9 pages, 2013.

[41] C. R. Farrar and G. H. James, "System identification from ambient vibration measurements on a bridge," Journal of Sound and Vibration, vol. 205, no. 1, pp. 1-18, 1997.

[42] S. W. Chen, Y. L. Xu, and R. C. Zhang, "Application of HHT method to system identification of Di Wang building during typhoon York," in Proceedings of the International conference on Advances in Building Technology, vol. 1-2, pp. 1115-1122, December 2002.

[43] Y. L. Xu, S. W. Chen, and R. C. Zhang, "Modal identification of Di Wang Building under Typhoon York using the HilbertHuang transform method," Structural Design of Tall Buildings, vol. 12, no. 1, pp. 21-47, 2003.

[44] W. Shi, J. Shan, and X. Lu, "Modal identification of Shanghai World Financial Center both from free and ambient vibration response," Engineering Structures, vol. 36, pp. 14-26, 2012.

[45] Y. Q. Ni, Y. Xia, W. Y. Liao, and J. M. Ko, “Technology innovation in developing the structural health monitoring system for Guangzhou New TV Tower," Structural Control and Health Monitoring, vol. 16, no. 1, pp. 73-98, 2009.

[46] H. Li, Z. R. Lu, and J. K. Liu, "Monitoring dynamic characteristics for a high-rise structure under different load environments," in Proceedings of the 15th International Conference on Experimental Mechanics (ICEM '12), 2012.

[47] Y. L. Xu, B. Chen, C. L. Ng, K. Y. Wong, and W. Y. Chan, "Monitoring temperature effect on a long suspension bridge," Structural Control and Health Monitoring, vol. 17, no. 6, pp. 632653, 2010.

[48] Y. Xia, B. Chen, X. Q. Zhou, and Y. L. Xu, "Field monitoring and numerical analysis of Tsing Ma suspension bridge temperature behavior," Structural Control and Health Monitoring, vol. 20, no. 4, pp. 560-575, 2013.

[49] J. Chen, Y. L. Xu, and R. C. Zhang, "Modal parameter identification of Tsing Ma suspension bridge under Typhoon Victor: 
EMD-HT method," Journal of Wind Engineering and Industrial Aerodynamics, vol. 92, no. 10, pp. 805-827, 2004.

[50] D. J. Yu and W. X. Ren, "EMD-based stochastic subspace identification of structures from operational vibration measurements," Engineering Structures, vol. 27, no. 12, pp. 1741-1751, 2005.

[51] J. P. Han, D. W. Li, and H. Li, "Application of Hilbert-Huang transform and stochastic subspace identification for modal parameter identification of civil engineering structures," in Proceedings of International Conference on Health Monitoring of Structure, Materials and Environment, vol. 1-2, pp. 216-221, 2007.

[52] J. P. Han, D. W. Li, and H. Li, "Modal parameter identification of civil engineering structures based on HilbertHuang transform," in Engineering Structural Integrity: Research, Development and Application, vol. 1-2, pp. 366-368, 2007.

[53] J. Xu, F. H. Ma, and S. X. Huang, "Application of HilbertHuang transform to identify modal parameters for large bridge," in Proceedings of the 4th International Symposium on Lifetime Engineering of Civil Infrastructure, pp. 478-481, 2009.

[54] X. H. He, X. G. Hua, Z. Q. Chen, and F. L. Huang, "EMD-based random decrement technique for modal parameter identification of an existing railway bridge," Engineering Structures, vol. 33, no. 4, pp. 1348-1356, 2011.

[55] J. N. Yang, S. L. Lin, and S. W. Pan, "Damage detection of a health monitoring benchmark building using Hilbert-Huang spectral analysis," in Proceedings of International Conference on Advances in Building Technology, vol. 1-2, pp. 1017-1024, December 2002.

[56] J. N. Yang, S. Lin, and L. Zhou, "Damage identification of a benchmark building for health monitoring," in Proceedings of the 1st International Conference on Structural Health Monitoring and Intelligent Infrastructure (SHMII '03), vol. 1-2, pp. 567-574, November 2003.

[57] S. Lin, J. N. Yang, and L. Zhou, "Damage identification of a benchmark building for structural health monitoring," Smart Materials and Structures, vol. 14, no. 3, pp. S162-S169, 2005.

[58] J. Liu, X. Wang, S. Yuan, and G. Li, "On Hilbert-Huang transform approach for structural health monitoring," Journal of Intelligent Material Systems and Structures, vol. 17, no. 8-9, pp. 721-728, 2006.

[59] S. J. A. Koh, M. Maalej, and S. T. Quek, "Damage quantification of flexurally loaded RC Slab using frequency response data," Structural Health Monitoring, vol. 3, no. 4, pp. 293-311, 2004.

[60] L. W. Salvino, D. J. Pines, M. Todd, and J. M. Nichols, "EMD and instantaneous phase detection of structural damage," in HilbertHuang Transform and Its Applications, vol. 5, pp. 227-262, 2005.

[61] N. E. Huang, K. Huang, and W. L. Chiang, "HHT-based bridge structural health-monitoring method," in Hilbert-Huang Transform and Its Applications, vol. 5, pp. 263-287, 2005.

[62] S. P. Wu, G. J. Qin, J. H. Zou, and H. Sun, "Structure health monitoring based on HHT of vibration response from unknown excitation," in Proceedings of the 8th International Symposium on Test and Measurement, vol. 1-6, pp. 490-493, 2009.

[63] Y. Dong, Y. Li, and M. Lai, "Structural damage detection using empirical-mode decomposition and vector autoregressive moving average model," Soil Dynamics and Earthquake Engineering, vol. 30, no. 3, pp. 133-145, 2010.

[64] C. Z. Qu and X. W. Lian, "Damage identification for transmission towers based on HHT," Energy Procedia, vol. 17, part B, pp. 1390-1394, 2012.
[65] H. Chen, Y. Yan, and J. Jiang, "Vibration-based damage detection of composite wingbox structures using improved hilberthuang transform," Key Engineering Materials, vol. 324-325, pp. 539-542, 2006.

[66] H. G. Chen, Y. J. Yan, and J. S. Jiang, "Vibration-based damage detection in composite wingbox structures by HHT," Mechanical Systems and Signal Processing, vol. 21, no. 1, pp. 307-321, 2007.

[67] R. A. Esmaeel and F. Taheri, "Delamination detection in laminated composite beams using the empirical mode decomposition energy damage index," Composite Structures, vol. 94, no. 5, pp. 1515-1523, 2012.

[68] E. A. Johnson, H. F. Lam, L. S. Katafygiotis, and J. L. Beck, "A benchmark problem for structural health monitoring and damage detection," in Proceedings of the 14th Engineering Mechanics Conference, ASCE, Austin, Tex, USA, May 2000.

[69] J. N. Yang, Y. Lei, and N. E. Huang, "Damage identification of civil engineering structures using Hilbert-Huang transform," in Proceedings of the 3rd International Workshop on Structural Health Monitoring, pp. 544-553, Stanford, Calif, USA, 2001.

[70] H. Sohn, A. N. Robertson, and C. R. Farrar, "Holder exponent analysis for discontinuity detection," Structural Engineering and Mechanics, vol. 17, no. 3-4, pp. 409-428, 2004.

[71] Z. Hou and M. Noori, "Application of wavelet analysis for structural health monitoring," in Proceedings of 2nd International Workshop on Structural Health Monitoring, pp. 946-955, Stanford University, Stanford, Calif, USA, 1999.

[72] Z. Hou, M. Noori, and R. S. Amand, "Wavelet-based approach for structural damage detection," Journal of Engineering Mechanics, vol. 126, no. 7, pp. 677-683, 2000.

[73] L. W. Salvino and D. J. Pines, "Structural damage detection using empirical mode decomposition and HHT," in Proceedings of the 6th World Multi Conference on Systemics, Cybernetics and Informatics, vol. 14 of Acoustics, Speech and Signal Processing, pp. 293-298, July 2002.

[74] J. N. Yang, Y. Lei, S. Lin, and N. Huang, "Hilbert-Huang based approach for structural damage detection," Journal of Engineering Mechanics, vol. 130, no. 1, pp. 85-95, 2004.

[75] Y. L. Xu and J. Chen, "Structural damage detection using empirical mode decomposition: experimental investigation," Journal of Engineering Mechanics, vol. 130, no. 11, pp. 1279-1288, 2004.

[76] B. Chen and Y. L. Xu, "A new damage index for detecting sudden stiffness reduction," in Proceedings of the 1st International Conference on Structural Condition Assessment, Monitoring and Improvement, pp. 63-70, Perth, Australia, 2005.

[77] B. Chen and Y. L. Xu, "A new damage index for detecting sudden change of structural stiffness," Structural Engineering and Mechanics, vol. 26, no. 3, pp. 315-341, 2007.

[78] B. Chen, Health monitoring and vibration control of large steel space structures [Ph.D. thesis], The Hong Kong Polytechnic University, 2007.

[79] B. Chen, J. Zheng, and J. P. Wang, "Damage assessment of reticulated shell under seismic excitations by using empirical mode decomposition," in Proceedings of the International Conference on Earthquake Engineering, pp. 248-252, Chengdu, China, May 2009.

[80] C. Bao, H. Hao, and Z. X. Li, "Multi-stage identification scheme for detecting damage in structures under ambient excitations," Smart Materials and Structures, vol. 22, no. 4, Article ID 045006, 2013. 
[81] S. T. Quek, P. S. Tua, and Q. Wang, "Detecting anomalies in beams and plate based on the Hilbert-Huang transform of real signals," Smart Materials and Structures, vol. 12, no. 3, pp. 447460, 2003.

[82] P. S. Tua, S. T. Quek, and Q. Wang, "Detection of cracks in plates using piezo-actuated Lamb waves," Smart Materials and Structures, vol. 13, no. 4, pp. 643-660, 2004.

[83] E. Douka and L. J. Hadjileontiadis, "Time-frequency analysis of the free vibration response of a beam with a breathing crack," NDT and E International, vol. 38, no. 1, pp. 3-10, 2005.

[84] C. C. Lin, P. L. Liu, and P. L. Yeh, "Application of empirical mode decomposition in the impact-echo test," NDT and E International, vol. 42, no. 7, pp. 589-598, 2009.

[85] S. K. Yadav, S. Banerjee, and T. Kundu, "Effective damage sensitive feature extraction methods for crack detection using flaw scattered ultrasonic wave field signal," in Proceedings of the 8th International Workshop on Structural Health Monitoring 2011: Condition-Based Maintenance and Intelligent Structures, vol. 1, pp. 167-174, September 2011.

[86] J. Meredith, A. González, and D. Hester, "Empirical Mode Decomposition of the acceleration response of a prismatic beam subject to a moving load to identify multiple damage locations," Shock and Vibration, vol. 19, no. 5, pp. 845-856, 2012.

[87] N. Roveri and A. Carcaterra, "Damage detection in structures under traveling loads by Hilbert-Huang transform," Mechanical Systems and Signal Processing, vol. 28, pp. 128-144, 2012.

[88] N. Cheraghi, M. J. Riley, and F. Taheri, "Application of HilbertHuang transform for evaluation of vibration characteristics of plastic pipes using piezoelectric sensors," Structural Engineering and Mechanics, vol. 25, no. 6, pp. 653-674, 2007.

[89] R. Kažys, O. Tumšys, and D. Pagodinas, "Ultrasonic detection of defects in strongly attenuating structures using the HilbertHuang transform," NDT and E International, vol. 41, no. 6, pp. 457-466, 2008.

[90] D. Rezaei and F. Taheri, "Health monitoring of pipeline girth weld using empirical mode decomposition," Smart Materials and Structures, vol. 19, no. 5, Article ID 055016, 2010.

[91] M. F. Ghazali, W. W. J. Staszewski, J. D. Shucksmith, J. B. Boxall, and S. B. M. Beck, "Instantaneous phase and frequency for the detection of leaks and features in a pipeline system," Structural Health Monitoring, vol. 10, no. 4, pp. 351-360, 2011.

[92] H. G. Chen, Y. J. Yan, W. H. Chen, J. S. Jiang, L. Yu, and Z. Y. Wu, "Early damage detection in composite wingbox structures using hilbert-huang transform and genetic algorithm," Structural Health Monitoring, vol. 6, no. 4, pp. 281-297, 2007.

[93] T. Ramesh Babu, S. Srikanth, and A. S. Sekhar, "Hilbert-Huang transform for detection and monitoring of crack in a transient rotor," Mechanical Systems and Signal Processing, vol. 22, no. 4, pp. 905-914, 2008.

[94] S. Pavlopoulou, W. J. Staszewski, and C. Soutis, "Evaluation of instantaneous characteristics of guided ultrasonic waves for structural quality and health monitoring," Structural Control and Health Monitoring, vol. 20, no. 6, pp. 937-955, 2013.

[95] Y. L. Xu and J. Chen, "Empirical mode decomposition for structural damage detection," in Proceedings of the 8th International Conference on Inspection, Appraisal, Repairs and Maintenance of Structural, pp. 147-154, Singapore, 2003.

[96] S. Liu, L. L. Zhou, G. Yan, and J. N. Yang, "HHT method for system identification and damage detection: an experimental study," in Proceedings of the 3rd International Conference on Earthquake Engineering: New Frontier and Research Transformation, pp. 825-829, 2004.
[97] D. Pines and L. Salvino, "Structural health monitoring using empirical mode decomposition and the Hilbert phase," Journal of Sound and Vibration, vol. 294, no. 1-2, pp. 97-124, 2006.

[98] D. Rezaei and F. Taheri, "Damage identification in beams using empirical mode decomposition," Structural Health Monitoring, vol. 10, no. 3, pp. 261-274, 2011.

[99] D. J. Chiou, W. K. Hsu, C. W. Chen, C. M. Hsieh, J. P. Tang, and W. L. Chiang, "Applications of Hilbert-Huang transform to structural damage detection," Structural Engineering and Mechanics, vol. 39, no. 1, pp. 1-20, 2011.

[100] J. P. Tang, D. J. Chiou, C. W. Chen, W. L. Chiang, W. K. Hsu, and T. Y. Liu, "A case study of damage detection in benchmark buildings using a Hilbert-Huang Transform-based method," Journal of Vibration and Control, vol. 17, no. 4, pp. 623-636, 2011.

[101] L. Lin and F. Chu, "Feature extraction of AE characteristics in offshore structure model using Hilbert-Huang transform," Measurement, vol. 44, no. 1, pp. 46-54, 2011.

[102] S. E. Hamdi, A. Le Duff, L. Simon, G. Plantier, A. Sourice, and M. Feuilloy, "Acoustic emission pattern recognition approach based on Hilbert-Huang transform for structural health monitoring in polymer-composite materials," Applied Acoustics, vol. 74, no. 5, pp. 746-757, 2013.

[103] A. Kunwar, R. Jha, M. Whelan, and K. Janoyan, "Damage detection in an experimental bridge model using HilbertHuang transform of transient vibrations," Structural Control and Health Monitoring, vol. 20, no. 1, pp. 1-15, 2013.

[104] W. K. Hsu, D. J. Chiou, C. W. Chen, M. Y. Liu, W. L. Chiang, and P. C. Huang, "Sensitivity of initial damage detection for steel structures using the Hilbert-Huang transform method," Journal of Vibration and Control, vol. 19, no. 6, pp. 857-878, 2013.

[105] L. D. Olson and R. R. Zhang, "Dynamic bridge substructure condition assessment with Hilbert-Huang transform for structural health monitoring," in Proceedings of the 1st International Conference on Structural Health Monitoring and Intelligent Infrastructure (SHMII '03), vol. 1-2, pp. 1109-1115, November 2003.

[106] R. R. Zhang, R. King, L. Olson, and Y. L. Xu, "Dynamic response of the Trinity River Relief Bridge to controlled pile damage: modeling and experimental data analysis comparing Fourier and Hilbert-Huang techniques," Journal of Sound and Vibration, vol. 285, no. 4-5, pp. 1049-1070, 2005.

[107] T. Y. Liu, W. L. Chiang, C. W. Chen, W. K. Hsu, L. C. Lu, and T. J. Chu, "Identification and monitoring of bridge health from ambient vibration data," Journal of Vibration and Control, vol. 17, no. 4, pp. 589-603, 2011.

[108] Y. L. Xu and J. Chen, "Characterizing nonstationary wind speed using empirical mode decomposition," Journal of Structural Engineering, vol. 130, no. 6, pp. 912-920, 2004.

[109] J. Chen and Y. L. Xu, "On modelling of Typhoon-induced nonstationary wind speed for tall buildings," Structural Design of Tall and Special Buildings, vol. 13, no. 2, pp. 145-163, 2004.

[110] Q. S. Li, J. R. Wu, J. Y. Fu, Z. N. Li, and Y. Q. Xiao, "Wind effects on the world's tallest reinforced concrete building," Proceedings of the Institution of Civil Engineers: Structures and Buildings, vol. 163, no. 2, pp. 97-110, 2010.

[111] Q. S. Li and J. R. Wu, "Time-frequency analysis of typhoon effects on a 79-storey tall building," Journal of Wind Engineering and Industrial Aerodynamics, vol. 95, no. 12, pp. 1648-1666, 2007.

[112] Y. Tian, Q. Yang, N. Yang, B. Li, and B. Chen, "Statistical spectrum model of wind velocity at Beijing Meteorological 
Tower," Science China Technological Sciences, vol. 54, no. 11, pp. 2869-2877, 2011.

[113] C. H. Hsieh and C. F. Dai, "The analysis of offshore islands wind characteristics in Taiwan by Hilbert-Huang transform," Journal of Wind Engineering and Industrial Aerodynamics, vol. 107-108, pp. 160-168, 2012.

[114] Z. Guo, W. Zhao, H. Lu, and J. Wang, "Multi-step forecasting for wind speed using a modified EMD-based artificial neural network model," Renewable Energy, vol. 37, no. 1, pp. 241-249, 2012.

[115] L. Ma, W. S. Han, J. X. Liu, and B. H. Ji, "Time-frequency analysis of nonlinear buffeting response of long-span bridge based on Hilbert-Huang transform," in Environmental Vibrations: Prediction, Monitoring, Mitigation and Evaluation, vol. 1-2, pp. 1220-1226, 2009.

[116] D. U. Park, N. S. Kim, and H. K. Kim, "Damping properties identified from wind-induced vibration measurements of a suspension bridge," in Proceedings of the 5th International Conference on Bridge Maintenance, Safety and Management (IABMAS '10), pp. 256-261, July 2010.

[117] X. Zhang, X. Du, and J. Brownjohn, "Frequency modulated empirical mode decomposition method for the identification of instantaneous modal parameters of aeroelastic systems," Journal of Wind Engineering and Industrial Aerodynamics, vol. 101, no. 1, pp. 43-52, 2012.

[118] J. Yi, J. W. Zhang, and Q. S. Li, "Dynamic characteristics and wind-induced responses of a super-tall building during typhoons," Journal of Wind Engineering and Industrial Aerodynamics, vol. 121, pp. 116-130, 2013.

[119] R. R. Zhang, "The Role of Hilbert-Huang transform in earthquakeengineering," in Proceedings of the World MultiConference on Systemics, Cybernetics and Informatics: Concepts and Applications (Part II), vol. 17, pp. 90-95, 2001.

[120] R. Zhang, "Applications of nonstationary, nonlinear data processing and analysis in earthquake engineering," in Proceedings of the 4th International Conference on Nonlinear Mechanics, pp. 721-727, 2002.

[121] R. R. Zhang, S. Ma, E. Safak, and S. Hartzell, "HilbertHuang transform analysis of dynamic and earthquake motion recordings," Journal of Engineering Mechanics, vol. 129, no. 8, pp. 861-875, 2003.

[122] J. Liang, S. R. Chaudhuri, and M. Shinozuka, "Simulation of nonstationary stochastic processes by spectral representation," Journal of Engineering Mechanics, vol. 133, no. 6, pp. 616-627, 2007.

[123] D. Yinfeng, L. Yingmin, X. Mingkui, and L. Ming, "Analysis of earthquake ground motions using an improved Hilbert-Huang transform," Soil Dynamics and Earthquake Engineering, vol. 28, no. 1, pp. 7-19, 2008.

[124] S. H. Ni, W. C. Xie, and M. D. Pandey, "Generation of modified earthquake time-histories using Hilbert-Huang Transform," in Proceedings of the 5th International Conference on Bridge Maintenance, Safety and Management (IABMAS '10), pp. 22192223, July 2010.

[125] C. H. Chen, C. H. Wang, J. Y. Liu et al., "Identification of earthquake signals from groundwater level records using the HHT method," Geophysical Journal International, vol. 180, no. 3, pp. 1231-1241, 2010.

[126] T. Wang, M. Zhang, Q. Yu, and H. Zhang, "Comparing the applications of EMD and EEMD on time-frequency analysis of seismic signal," Journal of Applied Geophysics, vol. 83, pp. 29-34, 2012.
[127] S. H. Ni, W. C. Xie, and M. Pandey, "Generation of spectrumcompatible earthquake ground motions considering intrinsic spectral variability using Hilbert-Huang transform," Structural Safety, vol. 42, pp. 45-53, 2013.

[128] Z. K. Lee, T. H. Wu, and C. H. Loh, "System identification on the seismic behavior of an isolated bridge," Earthquake Engineering and Structural Dynamics, vol. 32, no. 12, pp. 1797-1812, 2003.

[129] R. R. Zhang, "Characterizing and quantifying earthquakeinduced site nonlinearity," Soil Dynamics and Earthquake Engineering, vol. 26, no. 8, pp. 799-812, 2006.

[130] P. F. Alvanitopoulos, I. Andreadis, and A. Elenas, "Interdependence between damage indices and ground motion parameters based on hilbert-huang transform," Measurement Science and Technology, vol. 21, no. 2, Article ID 025101, 2010.

[131] Y. C. Wei, C. J. Lee, W. Y. Hung, and H. T. Chen, "Application of Hilbert-Huang transform to characterize soil liquefaction and quay wall seismic responses modeled in centrifuge shakingtable tests," Soil Dynamics and Earthquake Engineering, vol. 30, no. 7, pp. 614-629, 2010.

[132] N. E. Huang, "HHT: a review of the methods and many applications for nonsteady and nonlinear data analysis," in Proceedings of the World Multi-Conference on Systemics, Cybernetics and Informatics: Concepts and Applications (Part II), vol. 17, pp. 5966, 2001.

[133] S. Qin, B. Tang, R. Wei, and Y. Zhong, "HHT and a new method for removing white noise," in Proceedings of the 2002 International Conference on Noise and Vibration Engineering (ISMA '02), pp. 937-941, September 2002.

[134] X. M. Wang, F. L. Huang, G. Ma et al., "Application of empirical mode decomposition to process measured strain responses of a bridge," in Structural Condition Assessment, Monitoring and Improvement, vol. 1-2, pp. 940-944, 2007.

[135] A. J. Hu, L. Xiang, and G. J. Tang, "Vibration signal analysis based on hilbert-huang transform," in Proceedings of the 4th International Conference on Natural Computation (ICNC '08), pp. 646-650, October 2008.

[136] Z. K. Peng, P. W. Tse, and F. L. Chu, "An improved HilbertHuang transform and its application in vibration signal analysis," Journal of Sound and Vibration, vol. 286, no. 1-2, pp. 187205, 2005.

[137] J. Xun and S. Yan, "A revised Hilbert-Huang transformation based on the neural networks and its application in vibration signal analysis of a deployable structure," Mechanical Systems and Signal Processing, vol. 22, no. 7, pp. 1705-1723, 2008.

[138] J. W. Lin, "Mode-by-mode evaluation of structural systems using a bandpass-HHT filtering approach," Structural Engineering and Mechanics, vol. 36, no. 6, pp. 697-714, 2010.

[139] J. W. Lin, "A hybrid algorithm based on EEMD and EMD for multi-mode signal processing," Structural Engineering and Mechanics, vol. 39, no. 6, pp. 813-831, 2011.

[140] B. Chen, Z. W. Chen, Y. Z. Sun, and S. L. Zhao, "Condition assessment on thermal effects of a suspension bridge based on SHM oriented model and data," Mathematical Problems in Engineering, vol. 2013, Article ID 256816, 18 pages, 2013.

[141] J. C. Nunes, Y. Bouaoune, E. Delechelle, O. Niang, and P. Bunel, "Image analysis by bidimensional empirical mode decomposition," Image and Vision Computing, vol. 21, no. 12, pp. 1019-1026, 2003.

[142] A. Linderhed, "2-D empirical mode decompositions in the spirit of image compression," in Wavelet and Independent Component Analysis Applications IX, vol. 4738 of Proceedings of SPIE, pp. 1-8, April 2002. 


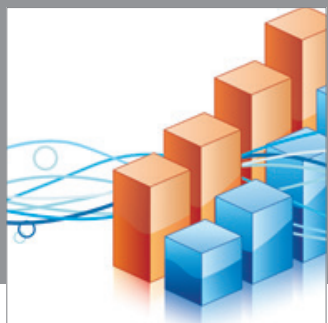

Advances in

Operations Research

mansans

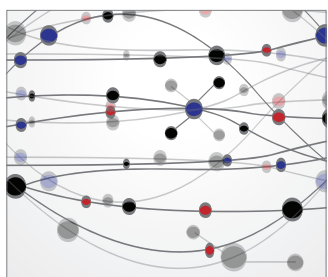

The Scientific World Journal
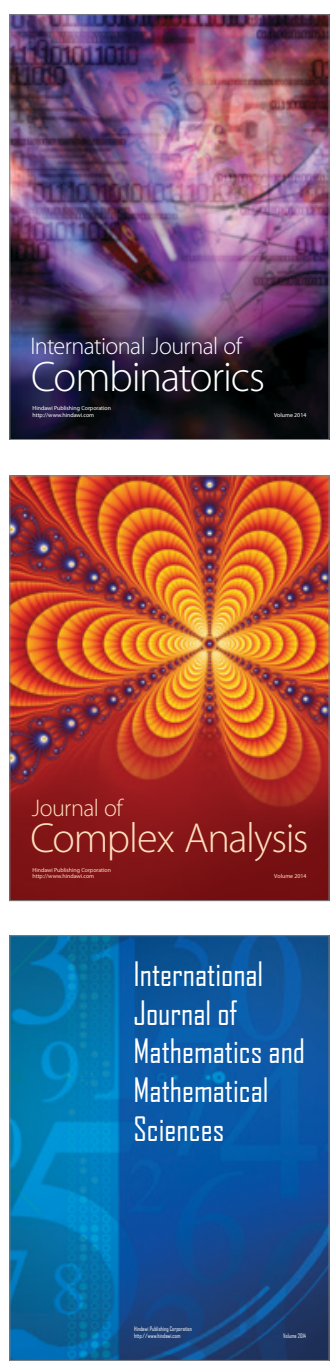
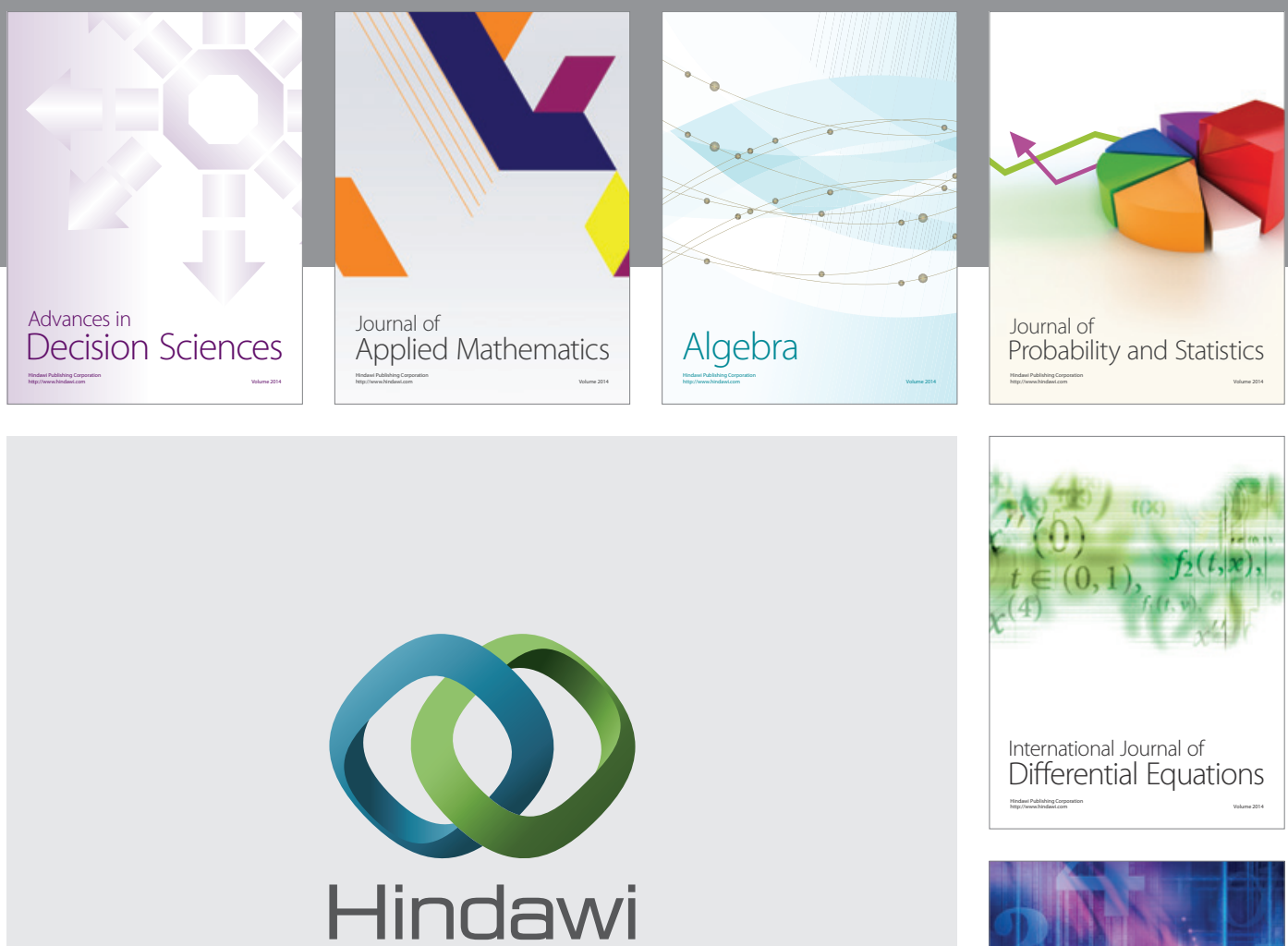

Submit your manuscripts at http://www.hindawi.com
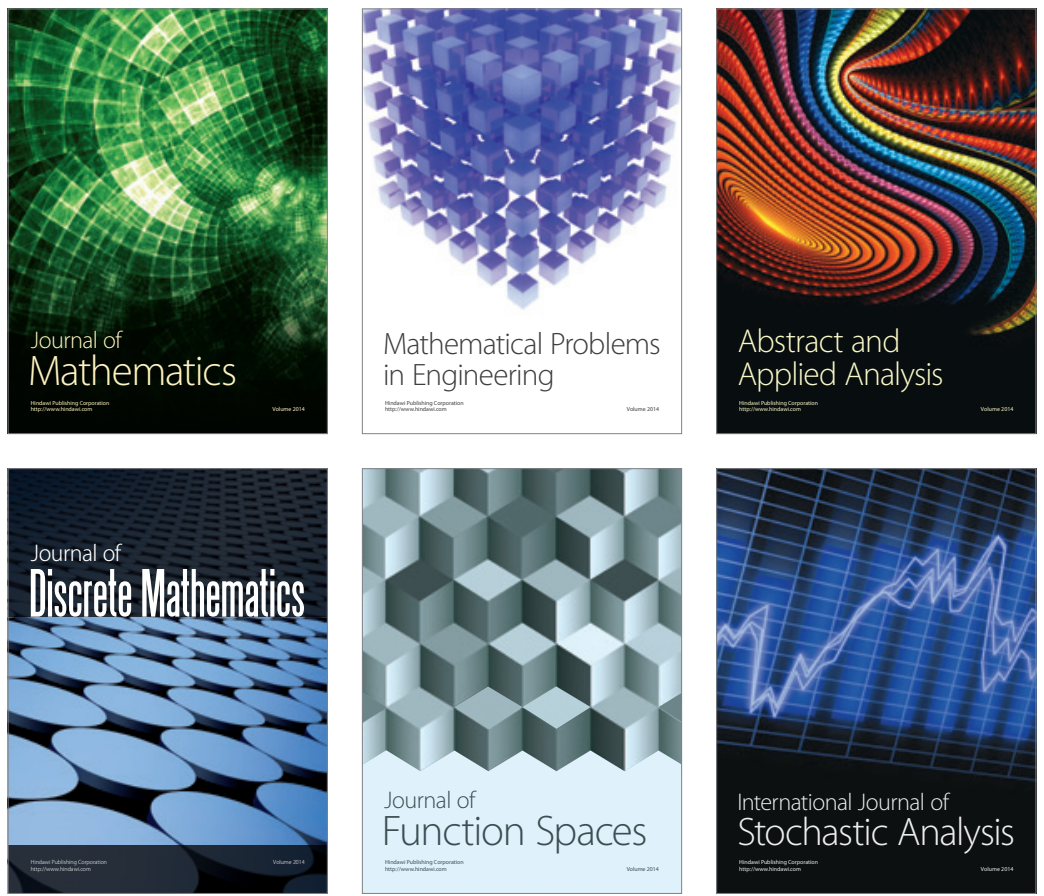

Journal of

Function Spaces

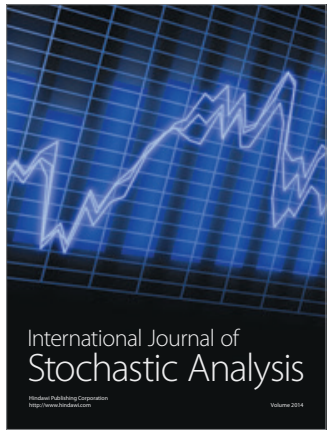

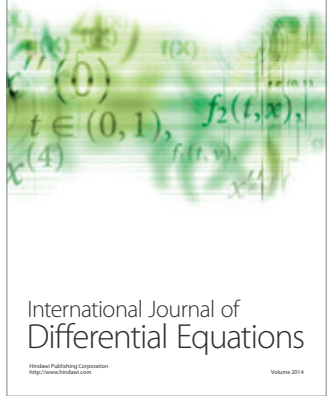
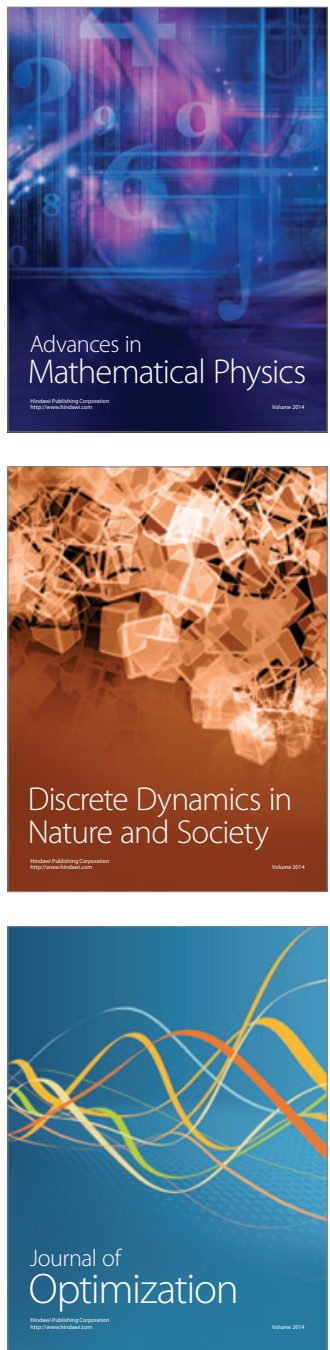